\title{
A Review: Molecular Concepts and Common Pathways Involving Vitamin $D$ in the Pathophysiology of Preeclampsia
}

\author{
Kareem Washington ${ }^{1,2}$, Somiranjan Ghosh ${ }^{3}$, Inez V. Reeves ${ }^{2 *}$ \\ ${ }^{1}$ Department of Genetics and Human Genetics, Graduate School, Howard University, Washington DC, USA \\ ${ }^{2}$ Department of Pediatrics and Child Health, Howard University College of Medicine, Washington DC, USA \\ ${ }^{3}$ Department of Biology, Graduate School, Howard University, Washington DC, USA \\ Email: ^ireeves@howard.edu
}

How to cite this paper: Washington, K., Ghosh, S. and Reeves, I.V. (2018) A Review: Molecular Concepts and Common Pathways Involving Vitamin D in the Pathophysiology of Preeclampsia. Open Journal of Obstetrics and Gynecology, 8, 198-229. https://doi.org/10.4236/ojog.2018.83023

Received: January 11, 2018

Accepted: March 12, 2018

Published: March 15, 2018

Copyright ( 2018 by authors and Scientific Research Publishing Inc. This work is licensed under the Creative Commons Attribution International License (CC BY 4.0).

http://creativecommons.org/licenses/by/4.0/ (c) (i) Open Access

\begin{abstract}
Preeclampsia is one of the most serious conditions at the end of pregnancy, causing increased perinatal morbidity and mortality to the pregnant mother and her product of conception. It remains a high-risk disease in ethnic minorities worldwide. Conception involves fetal invasion and implantation, followed by an actively forming and shedding decidua, an important uterine activity facilitating placental development. Dysregulation in conception mediates functional changes that induce onset of preeclampsia. The pathophysiology of preeclampsia primarily results from impaired trophoblastic invasion and implantation with subsequent vasculopathy. These events trigger exaggerated ischemic, inflammatory and immunologic events in the placenta bed that disrupt implantation. As the underlying mechanism(s) of preeclampsia remain obscure, there is increasing evidence that Vitamin D deficiency during pregnancy potentiates hypertensive states that could lead to the development of preeclampsia. As a prohormone, Vitamin D regulates molecular events within central pathophysiological pathways of implantation and vascular development. We review shared pathways involving Vitamin D modulation of pathologic events in implantation associated with preeclampsia. Understanding the causal mechanisms between Vitamin D and preeclampsia during early stages of conception could allude to development of candidate markers for treatment or screening, and decipher "hot spots" for research and intervention of, at-risk pregnant mothers.
\end{abstract}

\section{Keywords}

Vitamin D Deficiency, Preeclampsia, Gestational Hypertension, Placentation 


\section{Introduction}

Hypertensive states during pregnancy remain one of the three direct causes of maternal death globally [1] and a leading cause of early neonatal death in developing nations [2] [3]. This disease affects 3\% - 14\% of all pregnancies worldwide and $5 \%-8 \%$ in the USA [4]. Hypertensive disorders of pregnancy include chronic hypertension, which arises prior to pregnancy and gestational hypertension, a pregnancy-specific health event [5]. Gestational hypertension can induce an accelerated risk for developing preeclampsia [6], which is a life-threatening condition compromising the progression of normal human gestation [7]. Preeclampsia remains one of the leading causes of maternal morbidity, as premature delivery and/or uteroplacental insufficiency which causes a compromise of blood flow to the fetus, and neonatal mortality and morbidity worldwide [4] [8] [9] [10].

The clinical presentation of preeclampsia presents as a multi-system disorder [11] characterized by hypertension with [4] [12] or without proteinuria [7] [12] and edema [11] [13] [14]. It can be preceded by co-morbid conditions [15] and metabolic syndrome [16] [17] [18] prior to overt presentation [19]; nevertheless, it is devastating when presented earlier in pregnancy [20]. However, the clinical diagnosis of preeclampsia is about 20 weeks of gestation [21] [22] [23] [24] and can persist up to 4 weeks postpartum [11], beyond delivery of the placenta [2].

A preeclamptic pregnancy is a high-risk disease of population disparity, affecting underserved areas of the world [25] and ethnic minorities in the USA [6]. Although its etiologic events vary, there are studies indicating that it is associated with comorbid disorders of obesity [15], nulliparity [15] [26] [27], multiple gestation [19] [28] or with a family history of preeclampsia [29]. Preeclampsia is also more common in pregnancies resulting from egg donation, donor insemination, or in vitro fertilization [30], supporting the argument for immunologic tolerance of the mother. Interestingly, most patients with preeclampsia present with no identified risk factors [19] and preeclampsia recurrence risk increases with subsequent pregnancies [15] [26]. The sum of social, economic and ethnic disparities, comorbid medical conditions, fertility, genetic and environmental factors facilitate the development of preeclampsia.

Because the underlying pathology of preeclampsia predates its overt clinical presentation [18]; the concept for intervention focuses on early events. There are numerous reports that Vitamin D deficiency during pregnancy is a strong [31] and independent correlate to the development of early onset preeclampsia [6] [31] [32] [33]. Since preeclampsia is phenotypically multifactorial and vitamin D deficiency potentiates hypertension (renin-angiotensin system), immunologic competence (cytokine and immunoglobin regulation) and cell differentiation/proliferation (gene regulation), this suggests that Vitamin D deficiency potentiates hypertensive states of pregnancy via an underlying mechanism that is not fully understood.

Despite intense and numerous years of research, the etiology of preeclampsia 
remains obscure; its pathogenic mechanisms remain unresolved and awaits deciphering and intervention. Current knowledge confirms the primary pathophysiologic event is structural endothelial dysfunction during placental vascular development at the time of implantation [18]. Placental ischemia results in interferences to the normal adaptive responses to pregnancy. This pathology causes upstream triggers that perpetuates a generalized maternal systemic vasospasm, poor tissue perfusion and damage to many vital organs. This results in organ dysfunction. The disease severity relates to progressive maternal systemic vascular compromise [34]. It is well accepted that Vitamin D deficiency plays a role in a mother's risk to acquire early and severe preeclampsia [6] [31] [32] [33]. Current literature establishes that the relationship between shared common pathways of both Vitamin D and preeclampsia are more causal than casual. A review of the common and shared pathways is interpreted to hypothesize a mechanism that links early pathologic events beginning at implantation that involves vitamin $\mathrm{D}$ deficiency to clinical onset of preeclampsia. This review also seeks to identify and create "focal hot spots" for additional research and medical intervention.

\section{Placental Invasion, Implantation and Vasculogenesis}

The mammalian placenta is a vital organ of pregnancy, accepting the fetus as a semi-allogeneic product and functioning as the interface between maternal and fetal environments. This provides essential nutrients that regulate maternal-fetal hemodynamics. Normal pregnancy is associated with adaptive responses providing significant hemodynamic restructuring (physiologic) to ensure normal fetal growth. This restructuring process results in a decrease in total peripheral vascular resistance at the level of the placenta with an associated increase in maternal cardiac output, up to $30 \%$ to $45 \%$, without elevations in systemic blood pressure [35].

A. Normal implantation development (Figure 1): It is well established that normal pregnancy progresses in a series of sequential chronological events represented by inflammation (implantation), anti-inflammation (gestation) and inflammation (parturition) [16]. Signals from maternal uterine endometrium allow the invasion of fetal trophoblasts into the uterine decidua during the process of implantation [36] [37] [38]. This requires that the mother recognize the newly developing embryo as immunological "self" in order to accept the fetal trophoblast [39] as an anergic, semi-allogeneic product. This becomes the initial role of the mother's innate immune system [40].

Fetal cytotrophoblasts within the placenta differentiate into extravillous trophoblasts (EVT), which have an invasive phenotype [41]. A unique leukocyte subpopulation of maternal decidual Natural Killer (dNK) cells (uniquely identified as CD56 bright $\mathrm{CD}^{-} 6^{-}$), key components of the innate immune system, are massively recruited at the site of embryonic implantation (decidua basalis) [7]. $\mathrm{dNK}$ cells function is determined by the balance between inhibitory and activating receptors. Expression of inhibitory killer-cell immunoglobulin-like receptors (KIR2DL4) on dNK cells, which are capable of recognizing and binding to both 


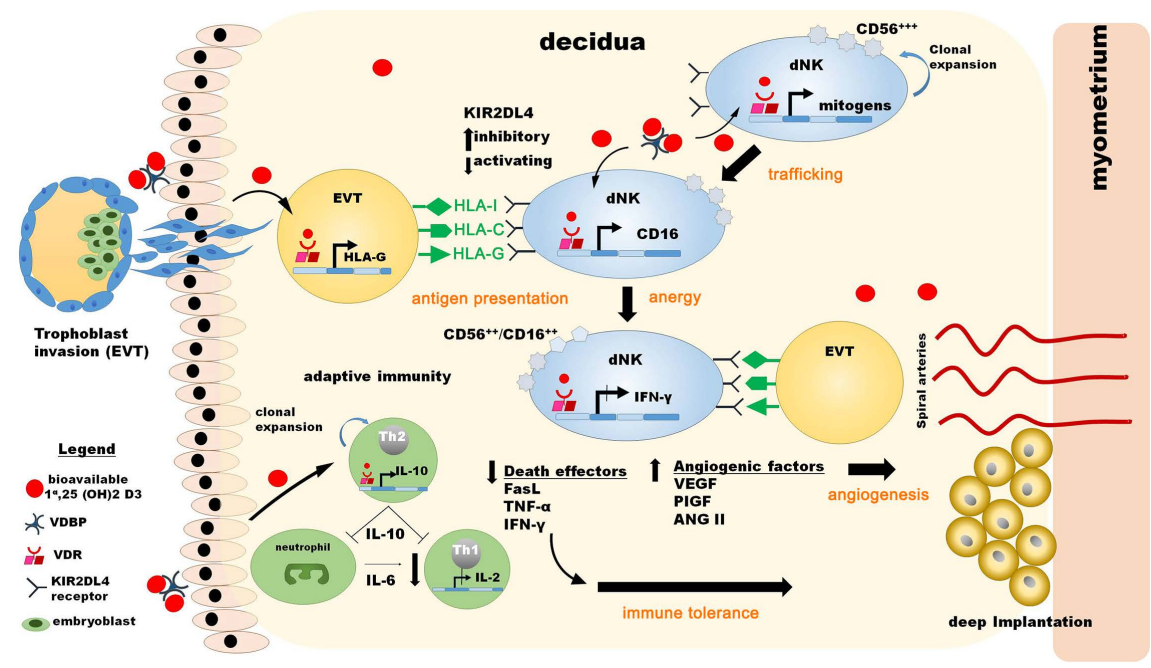

Figure 1. Events of normal implantation and placentation. Nutrigenomic role Vitamin D and common pathways of placental invasion, implantation, immune tolerance and vasculogenesis. Bioavailable Vitamin D is generated by conversion from D2 to D3 [1, 25 $(\mathrm{OH})_{2}$ D3] within decidua and trophoblastic cells and bound to VDBP. Ligand-bound VDR transcriptionally activates expression of HLA genes within EVT cells to mediate anergy. Vitamin D regulates expression of mitogenic and pathfinding genes in dNK cells that mediate trafficking within the decidua. Activated VDR in CD56 ${ }^{\text {br }} \mathrm{dNK}$ cells mediates anergy by upregulating $C D 16$ gene expression to produce the characteristic $\mathrm{CD} 56^{+} 16^{+}$ immune modulator phenotype. VDR bound ligand mediates repression of IFN $\gamma$ gene expression to confer dNK induced tolerance. Th-2 expression of $I L-10$ is modulated by bioactive Vitamin D which mediates Th2 proliferation, clonal expansion, and anti-inflammatory cytokine production.

the classical HLA-class I and non-classical HLA-C and HLA-G receptors [42] expressed by and presented on fetal-EVT [40], are necessary to establish the maternal-fetal interface. Ligand bound-KIR2DL4 receptor on dNK cells transduces signaling that confers inhibition of pathways which activate death effectors [43]. This promotes immune tolerance by the $\mathrm{dNK}$ cells to the invading semi-allogeneic trophoblasts. This mechanism of dNK-mediated anergic trophoblast is critical to successful implantation [44] [45] enabling progressive anchoring and invasion into the maternal decidua.

After acceptance by the maternal immune system, adequate spiral artery remodeling at the maternal-fetal interface [18] occurs, involving a highly choreographed cross-talk necessary for development of utero-placental perfusion [46]. Perfusion enables flow of nutrients to the developing fetus. The adaptive immune system plays a role in activating placental cell expression of chemokines and cytokines in a redundant manner [47] and growth factors that together modulate the implantation process [48]. Thereafter, a series of cytokine influxes are involved in angiogenesis and vascular stability, in particular VEGF, PIGF and angiotensin II (Ang-II) [49], leading to progressive placental perfusion [36] [50] [51].

Implantation in preeclampsia (Figure 2): Normal fetal EVT express increasing amounts of HLA-G with advancing invasive phenotype [45]. Genetic data have 


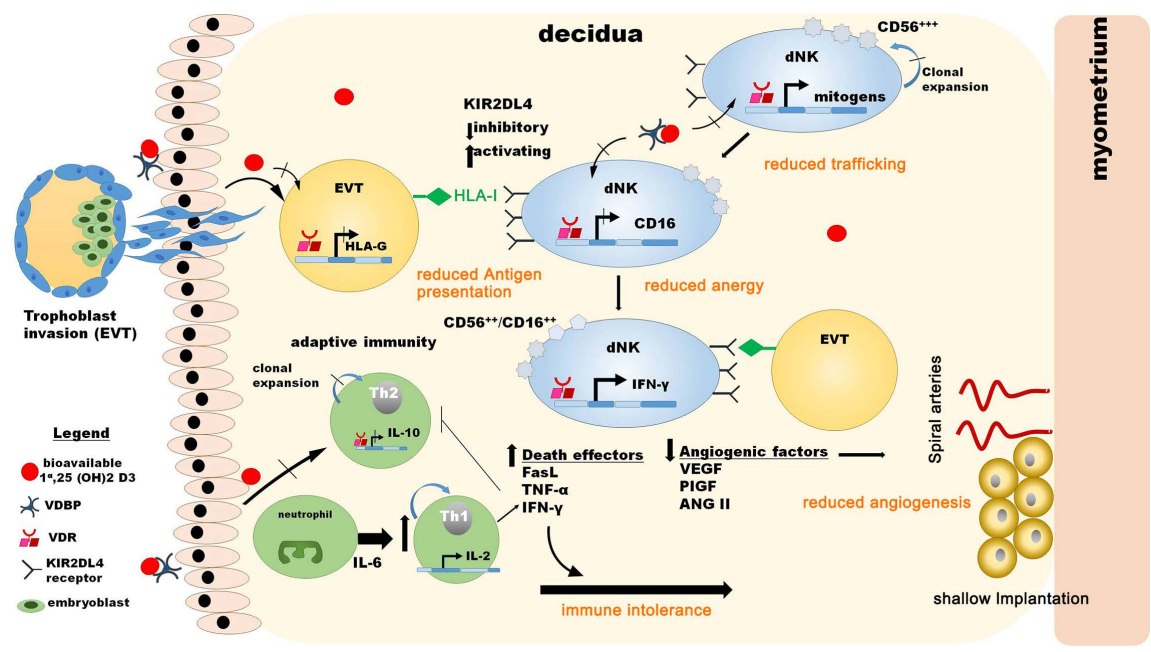

Figure 2. Events of implantation and placentation leading to preeclampsia. Nutrigenomic role of Vitamin D in pathologic pathways of placental invasion, implantation, immune tolerance and vasculogenesis. Loss or reduction of bioavailable Vitamin D caused by reduced conversion from D2 to D3 $\left[1,25(\mathrm{OH})_{2} \mathrm{D} 3\right]$ within decidua and trophoblastic cells and/or binding to VDBP is an early mechanism in hypertensive associated preeclampsia. Reduced concentration of D3 leads to insufficient activation of VDR transcriptional activity and therefore reduced expression of HLA genes within EVT cells which induce immune intolerance. Lack of bioavailable Vitamin D leads to reduced mitogenic proliferation of dNK cells. Non-activated VDR in CD56 ${ }^{\text {br }} \mathrm{dNK}$ cells do not produce expression of CD16 gene which mediates immune activation of death effect or gene expression in dNK cells. Loss of Vitamin D3 inhibition of IFN- gene leads to expression and immune-induced destruction of EVT cells. Th-2 expression of $I L-10$ is reduced by insufficient bioactive Vitamin D which confers increased IL-6 expression and up regulation of $\mathrm{CD} 4^{+} \mathrm{Th} 1$ induced cytokine mediated inflammation and immune intolerance.

shown that mutations which inhibit proliferation, trafficking, or expansion of dNK cells [36] [52] or a combination of defects in expression of maternal KIR2DL4 and/or fetal HLA-G and $H L A-C$ receptors [53] can challenge the mother's immunogenic tolerance for a successful implantation process, influencing the risk for preeclampsia [40]. Most preeclamptic placentae have absent or reduced HLA-G mRNA and protein expressions [36] on their trophoblasts making them vulnerable to attack by the maternal immune system. This results in decreased anchoring and invasive capability necessary to effectively form structurally stable and expansive maternal spiral arteries, this may be an etiologic mechanism for shallow placental invasion and penetration that initiates a cascade of systemic events associated with preeclampsia [24] [54].

Role of Vitamin D in implantation: Studies have demonstrated that Vitamin $\mathrm{D}$ receptors (VDR) are expressed on both placental decidua and fetal trophoblast cells in humans [55] [56]. Synthesis of 1, $25(\mathrm{OH}) 2 \mathrm{D}(3)$ is higher in first trimester decidual cells $(41+/-11.8 \mathrm{fmoles} / \mathrm{h} / \mathrm{mg}$ protein) compared to third trimester cells $(8+/-4.4 \mathrm{fmoles} / \mathrm{h} / \mathrm{mg}$ protein; $P<0.05)$. This suggest that Vitamin $\mathrm{D}$ may influence implantation by regulating expression of key target genes; as well as, modulating pleiotropic cross-talk of paracrine dialogue involving soluble HLA-G [57]. Chan et al. demonstrated intracrine VDR, in-vitro, responds to 
both precursor and metabolites of Vitamin D in a dose-dependent manner on human EVT from first trimester human pregnancies. There was a significantly increased EVT invasion with Vitamin D supplementation (maximal effect at 1 nM 1, 25-D3, 1.9-fold; $p<0.01$ and $100 \mathrm{nM} 25-\mathrm{D} 3,2.2$-fold; $p<0.05$ ) compared to untreated controls. These characteristic EVT expressed HLA-G markers of invasion were independent of cell viability. They concluded that dysregulated bioactivity of Vitamin D in uteroplacental tissues in combination with attenuated EVT invasion could be one of the mechanisms causing malplacentation, suggesting that Vitamin D deficiency modulates risk for pre-eclampsia [41].

\section{Immune System in Placentation}

Locally, decidualmonocytes, dendritic cells (DCs) and C CD4 $4^{+}$lymphocytes further modulate maternal immune tolerance, promoting myometrial invasion of trophoblast and subsequent vascular bed remodeling necessary for a successful implantation [23] [48].

Immune system in normal placental development. The maturation and activation of specific monocytes have various functions in implantation such as phagocytosis, antigen presentation and cytokine production. A state of induced immune tolerance of the mother for the fetus occur as: 1) DCs promote CD4 $4^{+}$ helper 2 (Th2) dominance, therefore decreasing the Th1/Th2 ratio; 2) increased numbers of regulatory $\mathrm{T}$ cells (Tregs) which produce anti-inflammatory cytokines like Interleukin 10 (IL-10) help regulate the adaptive immune system's response to placental ischemia [23]; and 3) an increase Treg/Th17 ratio which is favorable for immune tolerance [58]. This prevents vasoconstricting effects of endothelin-1 (ET-1) and reactive oxygen species (ROS) which are produced in response to ischemic conditions [23] [59]. Interestingly, interleukin 17 (IL-17) which is up regulated in many autoimmune disorders [23] is offset when this ratio is elevated.

Immune system in preeclampsia: The balance between Th1/Th2 is critical for healthy fetal implantation and pregnancy development. Th2 expressing cytokines (IL-4, IL-10 and TGF- $\beta$ ) are favorable for the maintenance of mammalian pregnancy [60]; whereas, Th1 cytokines (IL-2, IFN-, TNF- $\alpha$ ) are unfavorable since they are associated with rejection of the fetal allograft at the feto-maternal interface [61]. Placental ischemia in preeclampsia is associated with an immune imbalance where proinflammatory states are upregulated. There is a ratio bias between the two subpopulations of $\mathrm{CD} 4^{+} \mathrm{T}$ cells, Tregs and $\mathrm{Th} 17 \mathrm{~s}$, where a reversal of the Treg/Th17 ratio prevail due to Th17 upregulation. This results in an uncontrolled proinflammatory environment which causes unfavorable immunogenic responses to the fetal allograft [62]. The anti-inflammatory cytokines of Tregs (IL-10 and Th2 cells) that help regulate healthy immune response loses their protective function, stimulation and proliferation during inflammation [23]. In addition, Th17 produces IL17, a proinflammatory cytokine. Both Th17 and neutrophil migration increase TNF- $\alpha$ and IL- 6 in the myometrium, inducing massive inflammation that generate increased oxidative stress and ROS. 
These effects are additive when producing endothelial damage/dysfunction; and as such, studies have shown that decrease in Treg populations is directly proportional to the severity of preeclampsia [63]. It has been shown that this cascade of events resemble inflammation similar to autoimmune diseases and other immunologic conditions that ultimately result in the maternal loss of immune tolerance for the fetus during pregnancy [64].

The immune imbalance from placental ischemia, its resulting proinflammatory circulating $\mathrm{CD} 4^{+}$cells and their cytotoxic cytokines cause an excessive maternal humoral intravascular inflammatory response involving intravascular leukocytes traveling into the maternal systemic circulation, further injuring the vascular endothelial cell barrier [23]. Also, monocytes of the preeclamptic pregnancy are of different subpopulations. They produce increase amounts of oxygen free radicals and different cytokines (IL-12 and TNF- $\alpha$ ) [65] which contribute to the down regulation of T-cell activity [39] [66]. This further activates and recruits activated monocytes and, in combination, with activation of other inflammatory cells, such as granulocytes and endothelial cells, induce the full blown syndrome of preeclampsia [17]. A reduction in the supply of oxygenated blood to the uteroplacental unit (Placental ischemia) not only causes a robust oxidative stress response but also stimulates hypoxia-factors which produce vaso-occlusive and/or vasoconstrictive substances, such as soluble fms-like tyrosine kinase-1 (sFlt-1) and soluble endoglin (sEng) that contribute to the development of hypertension [23]. There is also decreased vasodilator nitric oxide (NO) and involvement of the adaptive immune pathway with B-cell production of autoantibodies that activate angiotensin II type I receptor (AT1).

Zenclussen et al. [61] showed a relationship between decidual expression of the Heme Oxygenase ( $\mathrm{HO}$ ) and $\mathrm{NO}$ in pregnant mice, along with a relationship to Th1/Th2 cytokine production. NO's vasodilatory role decreases systemic vascular resistance [67]. Previous observations suggested that regulation of the $\mathrm{HO}$ system is dependent on NO activity-both endothelial $\mathrm{NO}(\mathrm{eNO})$ and inducible NO (iNO) [68]. Purcell et al. described that increases in NO concentration during implantation could be necessary for developing adequate spiral artery structure within the myometrium and thus facilitating attachment [69]. Zenclussen et al. confirmed down-regulation of $\mathrm{HO}$ system in mice undergoing abortion accompanied by augmented Th1/Th2 cytokine ratio in a manner of pregnancy-incompatibility. This suggests that $\mathrm{HO}$ up-regulation is pregnancy-protective via decreasing the Th1/Th2 ratio or by protecting tissues from apoptosis [61]. Furthermore, sEng induction by hypoxia, impairs binding of TGF- $\beta$ to its receptors which leads to dysregulated TGF- $\beta$ signaling in the vasculature; this mechanism was shown to inhibit formation of capillaries, in vitro, and induce vascular permeability and hypertension, in vivo [14]. Additionally, sEng has a downstream effect on e NOS activation and vasodilation [70].

In summary, lack of vascular remodeling produces placental ischemia, which induces shallow trophoblast invasion and expansion that contributes to an in- 
crease in uterine artery resistance over time. A reduced placental blood flow causes low oxygen and nutrient delivery that have the potential to restrict intrauterine fetal growth [7] [71]. We postulate that upregulation of anti-inflammatory cytokines at early stages of implantation will induce essential immune response(s) to the placental semi-allograft, preventing non-phagocytic oxidative burst from neutrophil mediated degradative/necrotic mechanism and facilitate placental implantation.

Vitamin D in Immune effect of placentation: The interaction of 1, $25(\mathrm{OH}) 2 \mathrm{D}$ (Calcitriol) with its nuclear receptor (calcitriol receptor) is an active holo-transcription factor. It influences activation or repression of gene transcription. Nuclear receptors for 1, $25(\mathrm{OH}) 2 \mathrm{D}(3)$ are present in a range of tissues including the placenta [72] [73]. Placental and decidual tissues synthesize 1, 25 $(\mathrm{OH}) 2 \mathrm{D}$ in dose-dependent concentration to reduce the proliferation of allogeneically stimulated lymphocytes and cytotoxic cell generation [74] during early gestation. A functional Vitamin D enzyme system is present on dNK cells, making them more sensitive to calcitriol than their peripheral blood counterparts [75].

Vitamin D experiments have suggested that it modifies uncontrolled proinflammatory environments manifested during hypoxia-induced preeclampsia [62]. Through transcriptional activation of mitogenic genes in Th2 cells, bioavailable Vitamin D modulates the balance between Th1/Th2 cell ratio in favor of Th2 proliferation [48] [62]. Vitamin D also increases the transactivation of IL-10 and transrepresses the expression of Th1 mediated proinflammatory cytokines such as IFN-, IL-2 and TNF- $\alpha$ [76]. One study illustrated that the proportion of TNF- $\alpha$-expressing Th cells was significantly higher during Vitamin D deficiency [77]. IL-10, produced by Tregs [78] in response to ischemia, can limit oxidative stress, and with the presence of calcitriol at the feto-maternal interface, modulates the immunological milieu to prevent rejection of the fetal allograft. [48].

Smith et al. observed that deficiency in Vitamin D causes a cascade of changes in cytokine expression that closely mirrors the changes of inadequate trophoblastic invasion [76]. Proinflammatory cytokines are commonly elevated during preeclampsia [78]. In an experiment conducted by Diaz et al., proinflammatory conditions were mimicked in cultured trophoblastic cells inducing elevated cytokines; TNF- $\alpha$ stimulated increases in IL-6 and INF- concentration as well as their gene expressions. The presence of calcitriol resulted in a dose-dependent inhibition of expression of TNF- $\alpha$ and IL-6, down-regulating their proinflammatory nature in the preeclampsia placental cultures. Calcitriol treatment also resulted in a decreased concentration of mRNA and protein of all three cytokines (TNF- $\alpha$, stimulated IL-6, INF-) and that the highest calcitriol concentration resulted in reduced gene expression with values similar to those observed in control experiments [62]. Other studies also report that calcitriol suppressed inflammatory IFN- $\gamma$ RNA expression on in uterine NK ( $\mathrm{uNK}$ ) cells by seven-fold [75]. 
Other immune modulatory roles of Vitamin D include: 1) potent regulation of antibacterial cytokine production by uNK cells including cathelicidin antimicrobial peptide (CAMP) (Evans, Nguyen et al. 2006) [75]; 2) suppresses adverse inflammatory adaptive responses to successful implantation [75]; 3) plays a pivotal role in B cell immunity, which down regulates B-cell proliferation, plasma cell differentiation and IgG secretion; 4) Calcitriol is also known to additionally induce TGF- $\beta$ [48]; and 5) it is an important mediator of innate immune response affecting peripheral blood monocytes. Monocyte expression of toll-like receptor 4 (TLR4) are modulated by Vitamin D. When Vitamin D deficiency or insufficiency showed a tendency to increase the percentage of peripheral blood $B$ cells, this could be partially restored with 1, $25(\mathrm{OH}) 2 \mathrm{D}$ supplementation with improved cellular immunity and placentation [77]. In instances when another macrophage produced cytokines, TGF- $\beta$ interacts with NK cells to inhibit cytotoxicity of fetal trophoblasts. In the absence of Vitamin D, TLR4 becomes proinflammatory. Monocytes from preeclampsia patients express significantly increased levels of TLR4 and produce high concentrations of proinflammatory cytokines: TNF- $\alpha$, IL-6 and IL-1. In a study conducted by Qian et al., 2000 IU calcitriol supplementation for 12 consecutive weeks to preeclamptic women showed a significant lowering of both the mean fluorescence intensity and the positive percentage of monocytes expressing TLR4 compared to the placebo group, as well as reducing the concentrations of secreted TNF- $\alpha$, IL- 6 , and IL-1, yet the concentration of IL-10 was higher. By inhibiting the expression of peripheral blood TLR4 through Vitamin D3 supplementation, the incidence of preeclampsia lowered [78]. There is a link between CYP $27 \mathrm{~B} 1$ and immune function in the decidua which correlates with expression of TLR4 could indicate that Vitamin D may act in an autocrine/paracrine fashion in its regulation of both acquired and innateimmune responses [56].

\section{Heme 0xygenase-1 in Placentation}

Heme oxygenase-1 (HO-1) is expressed in the placenta [79] [80] [81] at a level comparable to that of the normal spleen, a tissue known for having high heme-oxygenase activity [82]. HO-1 is an inducible $\sim 32 \mathrm{kDa}$ protein which participates in breakdown of the heme-complex to generate equimolar amounts of biliverdin, free iron and carbonmonoxide. The degradation of hemoglobin by HO-1 can occur in virtually every cell [83]. Cell free heme-complexes can be generated from hemolysis, myolysis, ischemia/reperfusion, and other pathologic states. We postulate that cell free heme is a product of residual differentiation, shedding, and apoptosis from normal processes of placentation and implantation. Hence, concentration expected to increase in pathological states of inflammation and immune intolerance during abnormality of implantation. Studies have shown that HO-1, a rate limiting enzyme in hemoglobin degradation, is important in the regulation and maintenance of placental vascular development (angiogenesis and matrix remodeling of placental vessels) in early pregnancy 
[84]. Under physiologic conditions, these metabolic byproducts result in the following biological properties: antioxidants, vasodilatory, anti-thrombotic, anti-inflammatory, antiapoptotic and cytoprotective [85] [86]. The vasodilatory properties of heme catabolism is mediated mainly through endogenous carbon monoxide production that contributes significantly to the reduction of maternal peripheral vascular resistance and blood pressure [79]. Carbon monoxide can influence vascular tone independently [87] or influence other cytoprotective (anti-apoptotic, anti-inflammatory, antioxidant), vasoregulatory [88] or inhibitory effects in platelet aggregation pathways synergistic to $\mathrm{NO}$ [83], further protecting vascular integrity. HO-1 expression is also induced by oxidative stress [89] to protect against vascular ischemia-reperfusion injury [46] during spontaneous vasoconstriction [90]; and, its induction depends on gene transcription and protein synthesis [89]. The cellular protective function of HO-1, when expressed in endothelial cells, inhibits inflammatory responses which leads to graft acceptance [91]. HO-1 catabolizes heme to avoid toxic intracellular accumulation of free heme, preventing oxidative damage [92].

HO-1 and preeclampsia: In humans, HO-1 polymorphisms have been associated with a spectrum of compromise to placental development [86] [93] including placental spiral artery remodeling [80]. Any genetic polymorphism of HO-1 affects placental development with similar pathological, biochemical and clinical changes as preeclampsia [80] [88]. Most tissues express HO-1 at relatively low levels under homeostatic conditions; however, when stimulated by stress, transcriptional activation of the HO- 1 gene is rapidly induced. HO-1 gene expression is induced by a variety of stimuli besides stress, to include proinflammatory mediators such as interleukins (IL- $1 \alpha$, IL- $1 \beta$, IL- 6 and IL-11) and cytokine (tumor necrosis factor- $\alpha$ ) [94]. Studies have shown that HO-1-deficiency is associated with reduced stress defense and a proinflammatory tendency with susceptibility to vascular damage [10]. Stressed mammalian cells up regulate HO-1 during hypoxia-ischemia-reperfusion vascular injury as an adaptive mechanism to protect cells from oxidative damage. Its presence is a sensitive and reliable indicator of cellular oxidative stress. When oxidative stress occurs, high levels of oxygen free radicals are produced causing lipid peroxidation and endothelial lining damage [95]. The presence of cellular antioxidants, like HO-1, become crucial to reduce oxidative stress and prevent free radicle damage to blood vessels [10]. It is proposed that complications of pregnancy, such as recurrent miscarriages, intrauterine growth retardation and preeclampsia are associated with HO-1 deficiency [80].

Vitamin D and HO-1 regulation: Hypoxia/oxidative stress, characteristic of placental trophoblastic dysfunction in preeclampsia, is also associated with imbalance between two cyclooxygenase metabolites, arachidonic acid thromboxane (TXA) and prostacyclin (PGI). A state of hypoxia/oxidative stress manifests increased TXA (a potent vasoconstrictor and facilitator of platelet aggregation) and a decreased prostacyclin production (a potent vasodilator) [96]. Experi- 
mental results published by Sun et al., pretreatment of 1, $25(\mathrm{OH}) 2 \mathrm{D}(3)$ to their hypoxia/oxidative stress model resulted in a significantly reduced TXA and reduced ratio of TXA to PGI, suppressing hypoxia/oxidative stress. Although there was no effect on HO-1 upregulation, its effect on prostacyclin dominance could promote circulation and retard thrombosis in the placenta [95]. Although Vitamin $\mathrm{D}$ has been shown to reduce oxidative stress by lowering the plasma oxidative stress marker and reducing inflammation during pregnancy-induced hypertension [97], its direct role on HO-1 pathways remain to be clarified [98].

\section{Angiogenic Balance}

Normal: The invasion of trophoblast into the placenta bed occurs as it adopts an endothelial phenotype with adhesion molecules for subsequent angiogenesis to evolve [2]. The ideal vascular endothelium becomes a critical barrier and the primary sensor of physical and chemical changes in the bloodstream [9]. It has the following complex roles: 1) to control the passage of fluid into tissue, 2) for cellular trafficking that prevents damage from ROS, 3) as an inhibitor of coagulation and 4) to regulate vascular smooth muscle tone (blood pressure) through the release of vasodilatory (NO working synergistically with prostacyclin) and vasoconstricting agents (like ET-1, Ang-II and thromboxane A2) [99]. Excess shedding of cellular debris by the syncytiotrophoblast (syncytial apoptosis) cause the release of microparticles [100] into the maternal circulation as part of a normal process of turnover and repair [101].

Preeclampsia and angiogenic imbalance (Figure 3): Poorly developed blood supply through the placental vascular bed results in progressive placental hypoperfusion [101] and its resultant ischemia [7]. Lactate dehydrogenase (LDH) production has been used as an early clinical marker of anaerobic metabolism; progressive LDH elevation reflects the severity of the hypoxic condition [27].

The pathologic hallmark of preeclampsia is endothelial cell injury and dysfunction. It is associated with altered regulatory vascular responses that lead to pathologic consequences of dysregulated systemic and placental immunity [102] [103]. There is upregulation of adhesion molecules, generation of chemokines such as macrophage chemoattractant peptide-1) [99], production of pro-coagulative circulating markers of endothelial cell injury, [plasminogen activator inhibitor-1 (PAI-1)] [9] [99] [103], cellular fibronectin, factor VIII antigen [104] and vasoconstrictive cytokine (ET-1) [24]. This prothrombotic state is seen in women as progressive symptoms of preeclampsia. Endothelial dysfunction is an encompassing term resulting in a shift from a normal, healthy endothelium to a stressed/damaged endothelium that acquire a proinflammation, pro-coagulation and pro-vasoconstriction phenotype [99] [103]. This phenotype is characterized by reduced NO availability, which may stem from either decreased NO production or from increased NO inactivation [105]; there is free radical damage causing detachment and apoptosis of endothelial cells [99]. 


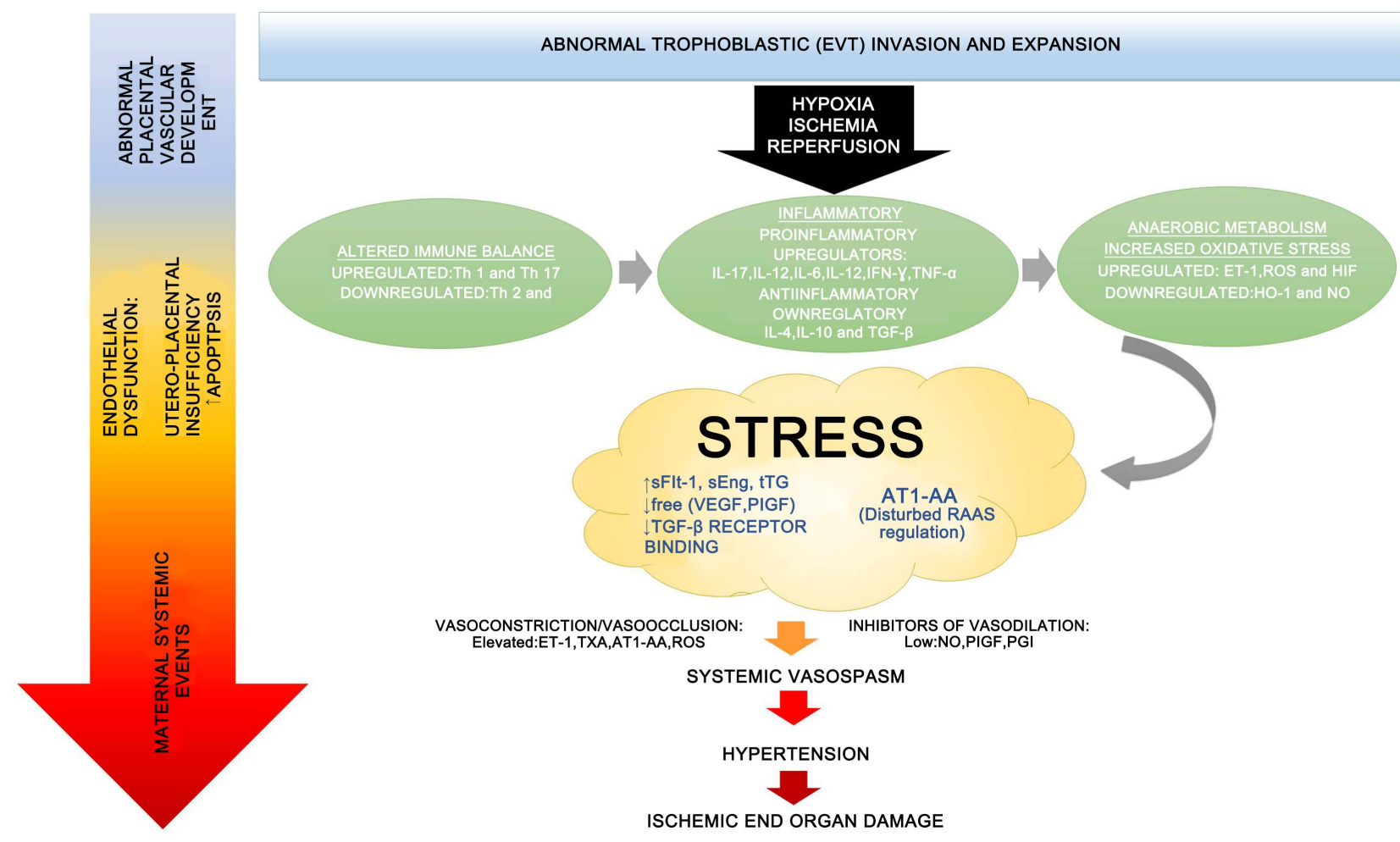

Figure 3. Schematic progression to preeclampsia following abnormal EVT invasion.

During preeclampsia, there is a non-physiologic increase in syncytiotrophoblast apoptosis [104] [106] results in an increased syncytial debris (and knot formation) released into the maternal circulation [101] in an unscheduled manner. Candidate substances of excessive syncytial shedding into the maternal plasma during endothelial dysfunction act to provoke a maternal syndrome; they may serve to elevate antiangiogenic [107] substances. This pathophysiology is associated with upstream triggers of antiangiogenic promoters when angiogenic promoters [19] [108] are down regulated. The down regulation may involve other proangiogenic pathways, such as nitric oxide, heme oxygenase and hydrogen sulfide. Imbalances due to upregulated antiangiogenic promotors are evident when oxidative stress cause evolution of autoantibodies [2].

The angiogenic imbalance favors the presence of several highly circulating antiangiogenic factors [109] of various sizes, shed from damaged placental endothelium [9] [46], that can be detected as early as $11-14$ week of gestation [110] prior to the onset of preeclampsia. The circulating antiangiogenic factors which have been used as predictive biomarkers of preeclampsia are: high levels of sFlt-1, sEng [14] [19] and tissue transglutaminase (tTG) [12] and decreased circulating levels of free vascular endothelial growth factor (VEGF) [12] [14]. There are other circulating levels of cellular microparticles that are elevated during preeclampsia [14] [38] [46].

Angiogenic pathways allow free VEGF to bind to PIGF activating VEGF receptor type 2 (VEGFR 2) that supports vascular growth. SFlt-1, a unique receptor for VEGF, is produced primarily by the syncytiotrophoblast syncytial knots 
of the placenta [111]. Although the placenta produces sFlt-1 during normal pregnancy, higher amounts of sFlt-1 are produced from the hypoxic preeclamptic placentae [112]. Elevated sFlt-1 binds to free VEGF and PIGF in the maternal circulation, reducing each's binding affinity for their membrane receptor [113], there by inhibiting the effects of VEGF binding to PlGF on maternal endothelial cells and podocytes [114]. This reduces endothelial integrity and function [113] as well as placenta vascular growth [80]. Findings suggest that concentrations of sFlt-1 increases steeply about five weeks before the onset of clinical preeclampsia compared to controls; although, sFlt-1 normally increase in late gestation [113].

The relationship of sFlt-1 to angiogenic PIGF has been clinically studied in ethnic population with preeclampsia. African-American women with preeclampsia (means gestational age of 32.3 weeks and with high BMI) were found to have significantly lower levels of PlGF $(90.3 \pm 8.9 \mathrm{pg} / \mathrm{ml}$ versus $172.8 \pm 20.2$ $\mathrm{pg} / \mathrm{ml} ; p<0.01)$, higher sFlt-1 $(2087.3 \pm 200.1 \mathrm{pg} / \mathrm{ml}$ versus $1546.5 \pm 91.9 \mathrm{pg} / \mathrm{ml}$; $p<0.01)$ and a higher sFlt-1/PLGF ratio $(66.8 \pm 18.7$ versus $22.3 \pm 2.9 ; p<0.01)$ compared to racially-matched normotensive controls [108]. This increase sFlt-1/P1GF ratio paralleled a decrease in the free VEGF and free PIGF levels, suggesting a decrease in these angiogenic factors attributed to binding by sFlt- 1 . Low concentrations of PlGF during early gestation have been associated with greater risk of early-onset preeclampsia. Although low PlGF has not been shown to be a predictive marker for onset of preeclampsia at $\geq 37$ weeks [113], it has high sensitivity and negative predictive value for preeclampsia manifesting within 14 days of preeclamptic symptoms before 35 weeks' gestation [115]. Therefore, using PlGF-based tests for patients with suspected preeclampsia at 20 - 37 weeks could provide diagnostic accuracy and cost-effectiveness [116]. Other studies have shown that circulating antiangiogenic factor have played major roles for predicting the severity of preeclampsia, either alone or in combination, with other clinical parameters and chemical markers [12] [70] [110] [114] [117] early in gestation. It also has the potential to predict restricted fetal growth in advanced gestation [14] [118].

\section{Vitamin D and Vasculogenesis}

Vitamin $D$ and angiogenic imbalance: Experimental findings that Vitamin D regulates VEGF production remain unclear. Nevertheless, studies have associated low Vitamin D levels to markers of antiangiogenic factors; and that, in combination, are predictive of preeclampsia from midgestation with some degree of severity. A study by Wei et al. associated significantly lower PlGF levels in women with $25(\mathrm{OH}) \mathrm{D}<50 \mathrm{nmol} / \mathrm{L}$ as early as $12-18$ weeks gestation (median, 449.5$)$ vs. $25(\mathrm{OH}) \mathrm{D}>50 \mathrm{nmol} / \mathrm{L}(507.9 \mathrm{pg} / \mathrm{mL}), p=0.04)$ with a significantly lower intercellular Adhesion Molecule-1 (ICAM-1) level. Both soluble vascular adhesion Molecule-1 (VCAM-1) and ICAM-1 levels have interaction involving trophoblastic angiogenesis. ICAM-1 is important in stabilizing cell-cell interactions and facilitating leukocyte endothelial transmigration. In this study, 
both low maternal $25(\mathrm{OH}) \mathrm{D}$ and low PlGF levels were inversely associated with risk of preeclampsia; this risk was independent of each other. Also, although low Vitamin D was associated with elevated ICAM-1, there was no correlation to impaired angiogenesis since the risk for preeclampsia was associated with elevated VCAM-I which did not correlate with low Vitamin D level. Another study showed a composite of both $25(\mathrm{OH})$ D level along with sFlt-1/PlGF ratio at midgestation (15 - 20 weeks) were more predictive than either one alone (area under curve: 0.83 versus 0.74 and 0.67 , respectively) for the development of severe preeclampsia [119]. In a recent experimental work published by Song, et al., they induced preeclampsia (PE) in a rat model. The PE group had lower VEGF $(p<0.01)$ and higher plasma sFlt-1 and TNF- $\alpha(p<0.01$ for both) compared to pregnant controls. Vitamin D supplementation to the PE cohort on gestation days 14 - 19 restored angiogenic balance by a significant increase in VEGF, reduced sFlt-1 and reduced TNF- $\alpha$ compared to the untreated PE group. Vitamin D supplementation was also shown to reduce oxidative stress by lowering the plasma oxidative stress marker and reducing inflammation during pregnancy-induced hypertension [120].

VEGF is an endothelium-specific growth factor. Its angiogenic activity promotes vascular smooth muscle proliferation. The bio-active form, 1, 25- $(\mathrm{OH}) 2 \mathrm{D}$ (3) has functional synergism to stimulate VEGF expression in rat vascular smooth muscle cells (VSMC), based upon the presence of a Vitamin D response element(s) (VDRE) located within VEGF promoter regions. Low serum $25(\mathrm{OH})$ $\mathrm{D}$ or minimal binding to promoter regions may be associated with diminished VEGF production, leading to preeclampsia [121].

Vitamin D and endothelial cell development and repair. Endothelial colony forming cells (ECFCs), a sub-population of late growth endothelial progenitor cells, have proliferative and migratory properties at sites of vessel damage. They possess the ability to differentiate into mature endothelial cells; hence, participating in vessel repair and de novo development of the vascular endothelium. Fetal ECFCs possess the ability to transmigrate across the placenta and participate in de novo maternal vessel formation in the pregnant uterus when damaged during preeclampsia [122]. In vitro studies of ECFCs by Brodowski et al., umbilical cord blood serum from preeclamptic women exhibited inhibition to vascular tubule formation and migration as compared to uncomplicated controls. ECFCs also were inhibited during states of hypoxia or hyperoxia but not with normoxia. The addition of exogenous Vitamin $\mathrm{D}_{3}(1,25(\mathrm{OH}) 2 \mathrm{D})$, showed reversal of the adverse effects of ECFCs, with improved tubule formation and migration even after blocking the VDR $(p=0.049)$. Exogenous Vitamin D also enhanced ECFC function during hypoxia or hyperoxia; these effects were dependent on VDR activation. Blocking of the VEGF pathway impaired ECFC function during exogenous Vitamin D administration. However, it was noted that there was no significant relationship between maternal serum Vitamin D concentration and fetal ECFC response to the patient serum in cell culture $(p=0.45)$ [123]. 


\section{Review of Angiotensin II Type 1 Receptor Antibodies (AT1-AA)}

Preeclampsia: Placental ischemia promotes an immunological loss of self-tolerance which results in B cell secretion of AT1-AA. Additionally, trophoblastic factors released into the maternal circulation can lead to an excessive inflammatory response [104] which elevates Flt-1 (VEGF-inactivating) and promotes the production of AT1-AA [35] [124]. AT1-AA are IgG mediated agonistic, stimulatory autoantibodies that act directly on AT1 [125]. It is associated with suppression of both circulating renin and aldosterone levels. This disturbs the RAAS regulation via aldosterone during normal pregnancy, which provides a delicate balance by increasing intravascular volume at no expense to cardiac output [35].

AT1-AA are associated with increased angiotensin II (ANG-II) sensitivity during PE with a tendency to increase blood pressure at lower ANG-II stimulation [126] with vascular smooth muscle constriction [7]. These antibodies can be associated with greater severity of disease when present at midgestation [7]. The production of AT1-AA has been shown to mediate a path towards chronic inflammation [24]. Although AT1-AA may occur early, at the initial time of placental hypoxemia, its utility as a sensitive biomarkers to predict progression of preeclampsia needs more clarity [124].

Vitamin $D$ : There are studies that argue a beneficial role of Vitamin $\mathrm{D}$ on various hypertensive disorders of pregnancy related to AT1-AA. Studies investigating double-transgenic rats with excess Ang-II production fed Vitamin D-depleted (experimental group) chow for 3 weeks (short-term) showed higher mean systolic BP and upregulated angiotensin metabolites, including Ang-II, and its counter-regulatory breakdown product. This aggravated hypertension lead to target-organ damage [114]. They concluded that even a short-term severe Vitamin D deficiency may directly promote hypertension and impact the RAAS system that could contribute to target-organ damage [127]. Another study revealed that after 8-weeks of cholecalciferol therapy in hypertensive patients with hypovitaminosis D, there was a significant reduction in circulating renin-angiotensin-aldosterone and improved vascular function compared to controls [128]. Recently, it was confirmed that AT1-AA associated preeclampsia was reduced with Vitamin D supplementation in the RUPP rat, model of PE. The mechanism could have either lowered mean arterial pressure (MAP) in the hypertensive model without $\mathrm{PE}$ features or it was through downstream factors of AT1-AA [129].

\section{Candidate Hot Spots}

Pregnancy presents a challenging period when Vitamin D availability becomes essential to utero-placental sufficiency [130] [131], especially to deter early-onset pathophysiologic events of preeclampsia [132]. Clinically, Vitamin D sufficiency 
correlates with its "bioavailability", defined as the amount of $25(\mathrm{OH}) \mathrm{D}$ bound to vitamin-D binding protein (VDBP) in the serum [133] [134] [135] [136]. A deficiency or insufficiency could impact its steroidal and/or anti-inflammatory response to mitigate this illness associated with systemic inflammation. The focus is to identify candidate genes and/or pathway that prevent endothelial dysfunction.

We have presented review of the relationships between vitamin $\mathrm{D}$ bioavailability, gene expression and pathways involved in placentation, implantation and vasculogenesis during early stages of pregnancy. The metabolic pathway of Vitamin D is extensive and intricate with several challenging candidates that modulate risk of progressive gestational hypertension leading to preeclampsia [131]. They range from 1) vitamin D bioavailability: this involves seasonal changes [137], dietary factors [130] [131], environmental and/or genetic factors [138] [139] and ethnically related low affinity for VDBP [139]. Additionally, production and secretion of 1, $25(\mathrm{OH}) 2 \mathrm{D} 3$ during pregnancy by both the kidneys and placenta play a role in availability [140]; 2) polymorphism within kinetic and dynamic pathways of molecular activation [137] [138] and transport [141]; and/or 3) any dysfunctional alleles of the VDR [142] [143] that can influence the function of transcriptional activation of responsive genes [142] [144] [145] [146].

This argues a need for research analyzing vitamin D bioavailability to assess mothers at risk for these hypertensive disorders. There is growing evidence that VDBP also plays a role in immune modulation. Candidate genetic/phenotypic variants of group-specific globulin component (GC genes) of VDBP need further exploration for encoding protein that could modulate intervention(s) in pathophysiologic pathways of diseases [147]. Baca et al. have linked the combination of common genotypic allelic variants using single nucleotide polymorphisms (SNP) in VDR, GC genes of VDBP or cytochrome p450 27B1 (CYP27B1) as candidate markers, along with $25(\mathrm{OH}) \mathrm{D}$ concentration to identify pregnant women at risk for vitamin D bioavailability [148]. Another attractive area of focus as a biomarker of risk is the pathways for protecting against Vitamin D intoxication. Individual risk for bioavailable Vitamin D deficiency when uteroplacental demand is elevated may involve phenotypes that are "efficient" processors for converting pre-Vitamin D3 and Vitamin D to inactive metabolic products, potentially increasing one's risk for deficiency. Bioavailable Vitamin D3, that which is bound to VDBP and transported to cells, must be released at target cells, where unbound vitamin D3 diffuses across the membrane to bind VDR (mediate transcriptional regulation of responsive genes) or bind to calicitriol-VDR-complex (mediate non-transcriptional for modulating cellular functions such as survival, differentiation and proliferation). This suggests that further inquiry into the mechanism promoting uncoupling of ligand (Vitamin D) from binding protein at the cell surface may reveal mechanisms of pathogenesis. It is reasonable to speculate there may be a concentration gradient between 
bound and unbound Vitamin D3 or a ratio between any combination between $25(\mathrm{OH}) \mathrm{D}, 1,25(\mathrm{OH})_{2} \mathrm{D}$, and/or $24,25(\mathrm{OH})_{2} \mathrm{D}$ at the uteroplacental tissue that drives exchange in specific cells. Individuals insufficient in producing proper "exchange" ratios may display reduced cell response to adequate concentration of bioavailable Vitamin D in the presence of normal genes and gene products of VDBP, VDR and metabolic enzymes in the uteroplacental tissue.

Further research into the pathophysiology should seek to validate the role of hypovitaminosis $\mathrm{D}$ in inflammation mediated malplacentation. This has the potential to differentiate clinical events specific to Vitamin D insufficiency. We postulate that in the presence of normal levels of Vitamin D, at-risk individuals phenotypically have inadequate metabolism of bioavailable product, especially when its demand is high. This argues that Vitamin D dysregulation may be an early event in the pathway leading to gestation hypertension. Hence, future investigation analyzing the relationship between Vitamin D insufficiency and concentration of soluble HLA-G (sHLA-G) potentially could resolve biochemical link and association between Vitamin D, gestational hypertension, preeclampsia and uterine growth restriction. We hypothesize that inadequate placental metabolism of, and cell response to, Vitamin D could reduce expression of HLA-G and sHLA-G resulting in reduced activation of KIR2DL4 inhibitory signal transduction of UNK and dNK cells-mediating inflammatory process.

We recommend research to establish diagnostic toolkit to detect these high-risk pregnancies during early gestation. This should involve standardized measurement of Vitamin D levels by Mass Spectrometry (the gold standard). Genotyping VDBP and its common pathway allele variant to establish "bioavailability" [133] [134] [135] [136], as well as VDR associated with phenotypic low binding protein(s) need careful assessment. Markers of cell apoptosis should be developed such as Cell free DNA and Fluorescence Activated Cell Sort (FACS analysis) to detect apoptotic events of endothelial dysfunction.

\section{Conclusions}

From our review, we have demonstrated numerous causal relationships between preeclampsia and Vitamin D. As we tracked the events from inception of implantation (time of fetal EVT invasion) up to the third trimester of pregnancy, Vitamin D deficiency has remained a single nutritional condition that shares most of the adverse pathophysiology of preeclampsia (Table 1). The "Molecular Concept of Low Vitamin D" has been shown to potentiate preeclampsia through numerous and common pathways via both intracrine and/or paracrine mechanism(s). Many studies have used Vitamin D to reverse molecular and pathophysiologic changes of preeclampsia to a major extend. Research publications have documented that Vitamin D supplementation can promote a healthy pregnancy from inception, and prevent early insidious events leading to preeclampsia. 
Table 1. Established common pathways shared with preeclampsia and Vitamin D.

\begin{tabular}{|c|c|c|}
\hline Key factors & Preeclampsia studies & Vitamin D studies \\
\hline $\begin{array}{l}\text { Factors affecting placental } \\
\text { trophoblastic invasion, } \\
\text { implantation and } \\
\text { vasculogenesis. } \\
\text { Key factors: } \\
\text { Maternal: dNK cells, } \\
\text { KIR2DL4 } \\
\text { Fetal: HLA-G, HLA-C }\end{array}$ & $\begin{array}{l}\text { 1) dNK cells gene mutations with reduction in its } \\
\text { proportion or phenotype variation. } \\
\text { 2) Defects in genes expression of maternal KIR2DL4. } \\
\text { 3) Strong inhibitory effect of maternal dNK } \\
\text { cells KIR2DL4 ligand. } \\
\text { 4) Defects fetal HLA-G and HLA-C RNA gene } \\
\text { expression and protein. }\end{array}$ & $\begin{array}{l}\text { 1) Both decidua and trophoblastic cells express VDR. } \\
\text { 2) Human decidua produces } 1,25(\mathrm{OH}) 2 \mathrm{D}(3) \\
\text { throughout pregnancy with highest expression in the } \\
\text { first trimester. } \\
\text { 3) In vitro human isolates of incomplete human EVT } \\
\text { in first trimester express HLA-G. EVT responds to } \\
\text { both Vitamin D (metabolite and its precursor) with } \\
\text { significantly increased EVT invasion. Invasion was } \\
\text { independent of cell viability. }\end{array}$ \\
\hline
\end{tabular}

1) Vitamin $D$ restores the balance between Th1 and Th2 type cytokines. By favoring Th2 domination, it

1) Imbalance between two subpopulations of $\mathrm{CD} 4^{+} \mathrm{T}$ cells. Unfavorable, uncontrolled hypoxic-related proinflammatory environment prevails impairing fetal tolerance and implantation:

a) Reversal of Th1/Th2; down regulated favorable Th2 type cytokines (IL-4, IL-10 and TGF- $\beta$ ) for pregnancy success; Upregulated, unfavorable Th1 cytokines (IL-2, IFN- $V$, TNF- $\alpha$ )

b) Reversal of the proinflammatory Treg/Th17 ratio. Tregs decrease and Th17 increase. Th17 produces IL17; both Th17 and neutrophils cause massive inflammation generating oxidative stress; and the presence of increase in both TNF- $\alpha$ and IL- 6 contribute to endothelial damage/dysfunction. 2) Monocytes from preeclampsia patients express significantly increased levels of TLR4 and produce high concentrations of proinflammatory cytokines. 3) Abnormal systemic maternal humoral response.

modifies the uncontrolled proinflammatory environment resulting from the hypoxic state. 2) Vitamin D increases the expression of IL-10 and decreases the expression of Th1 mediated proinflammatory cytokines (IFN- $\gamma$, IL-2, and TNF- $\alpha$ ); this function limits oxidative stress during ischemia and prevents rejection of the fetal allograft.

3) TNF- $\alpha$-expressed in Th1 cells is significantly higher during Vitamin D deficiency. Calcitriol has a dose-dependent inhibition of the expression of TNF- $\alpha$ and IL-6, down-regulating their proinflammatory nature during hypoxia.

4) Calcitriol induces TGF- $\beta$ which interacts with NK cells, to allow acceptance of trophoblasts and avoid fetal cells death.

5) In the absence of Vitamin D, monocytes numbers and its TLR4 are decreased, reducing its ability to be proinflammatory.

6) Vitamin D is a potent regulator of CAMP an essential antibacterial hormone that supports successful implantation.

1) HO-1-deficiency is characteristic of preeclampsia. Any genetic polymorphism of HO-1 affects placental development and is associated with reduced stress defense (no response to proinflammatory cytokines

Role of HO-1 with increased susceptibility to vascular damage). 2) Hypoxia/oxidative stress cause increased TXA (a potent vasoconstrictor and facilitator of platelet aggregation) and decreased PGI (a potent vasodilator).

1) High circulating antiangiogenic factors: -(sFlt-1

Factors affecting placental angiogenesis:

Key factors: Angiogenic Vs. Antiangiogenic factors and sEng) as predictive biomarkers of preeclampsia. -African American with preeclampsia have angiogenic imbalance involving significantly lower levels of PIGF, higher sFlt-1 and a higher sFlt-1/PLGF ratio.

2) Low circulating angiogenic factors: -VEGF and PIGF.
1) Pretreatment of $1,25(\mathrm{OH}) 2 \mathrm{D}(3)$ to hypoxia/oxidative stress model resulted in a significantly reduced TXA and reduced ratio of TXA to PGI, to promote circulation and retard thrombosis in the placenta.

2) The direct role Vitamin Don HO-1 pathways remain to be clarified.

1) Vitamin D regulation of angiogenic factors remains unclear.

2) Maternal PIGF levels significantly lower with 25 $(\mathrm{OH}) \mathrm{D}<50 \mathrm{nmol} / \mathrm{L}$; and both low levels of maternal $25(\mathrm{OH}) \mathrm{D}$ and PlGF levels were inversely associated with the risk of preeclampsia.

3) Combining both $25(\mathrm{OH}) \mathrm{D}$ level and sFlt-1/PLGF ratio was more predictive than either alone for the development of severe preeclampsia.

4) The Vitamin D supplementation to PE-induced rat model group showed restoration of angiogenic balance and reduction of inflammation in PE-induced hypertension. 


\section{Continued}

\begin{tabular}{|c|c|c|}
\hline $\begin{array}{l}\text { Factors affecting placental } \\
\text { vasculogenesis } \\
\text { Key factors: Endothelial } \\
\text { colony forming cells }\end{array}$ & $\begin{array}{l}\text { 1) ECFCs in umbilical cord blood serum exhibit } \\
\text { inhibition to vascular tubule formation and } \\
\text { migration. } \\
\text { 2) Low or minimal binding of VDRE to VEGF } \\
\text { promoter sites may be associated with diminished } \\
\text { VEGF production, leading to } \\
\text { preeclampsia. }\end{array}$ & $\begin{array}{l}\text { 1) Exogenous (1, } 25(\mathrm{OH}) 2 \mathrm{D}(3) \text { reverses adverse } \\
\text { effects of ECFCs, with improved tubule formation } \\
\text { and migration. } \\
\text { 2) The active form, } 1,25(\mathrm{OH}) 2 \mathrm{D}(3) \text {, has } \\
\text { functional synergism to stimulate VEGF expression } \\
\text { of rat VSMC when VDRE binds to both of the } \\
\text { VEGF promoter sites. }\end{array}$ \\
\hline $\begin{array}{l}\text { Factors affecting placental } \\
\text { Loss of immune } \\
\text { tolerance } \\
\text { Key factors: ANG-II } \\
\text { and AT1-AA. }\end{array}$ & $\begin{array}{l}\text { 1) An immunological loss of self-tolerance during } \\
\text { placental ischemia results in B cell secretion of } \\
\text { AT1-AA, affecting the RAAS system. This results in } \\
\text { vasoconstriction and intravascular fluid } \\
\text { distribution. }\end{array}$ & $\begin{array}{l}\text { 1) Vitamin D down regulates B cell proliferation, } \\
\text { plasma cell differentiation and IgG antibodies } \\
\text { secretion. } \\
\text { 2) AT1-AA associated with preeclampsia were } \\
\text { reduced with Vitamin D supplementation in the } \\
\text { RUPP rat model of PE. } \\
\text { 3) Short-term severe Vitamin D deficiency in rats } \\
\text { had higher mean systolic BP and upregulated } \\
\text { Ang-II and its counter-regulatory breakdown } \\
\text { product. This aggravated hypertension and } \\
\text { target-organ damage. } \\
\text { 4) 8-week of cholecalciferol therapy in hypertensive } \\
\text { patients with hypovitaminosis D significant showed } \\
\text { circulating renin-angiotensin-aldosterone levels and } \\
\text { vascular function improved. }\end{array}$ \\
\hline
\end{tabular}

We speculate there is an evolutionary significance that low affinity of VDBP for D2/D3 Vitamin D as an adaptation to prevent toxic levels of Vitamin D in the body; however, this may also be an environmental risk for individuals with hypertension. Hence, we postulate that minorities homozygous for specific GC allele of the VDBP may require personalized higher amount of Vitamin D in their prenatal care to reduce the risk of gestational hypertension, preventing preeclampsia.

Considering the complicated pathways resulting in preeclampsia, we have identified many hot spots associated with a central molecular concept. Vitamin $D$ remains an early identifiable nutrigenomic substance that has the potential to prevent progression to preeclampsia. Randomized controlled clinical studies involving more high-risk ethnic populations (with comparable genotyping) is most desired to understand these pathologic candidate markers of Vitamin D. A scientific approach will decipher personalized Vitamin D dosing and serum levels, along with any preventable pathway polymorphism that have the potential to compensate for any dysfunctionality. Translational research is highly desired to identify key candidate genes/markers contributing to abnormalities in the Vitamin D pathway, in order of early relevance for diagnosis and monitoring vulnerable pregnancies at risk for preeclampsia. Early and sensitive tools are most desired to be used prior to 14 weeks of pregnancy. A robust advocacy is immediately needed for all pregnant women to have early access to prenatal care as well as provider awareness to make early diagnosis and corrective management of risk factors that develop into preeclampsia during pregnancy. 


\section{References}

[1] Say, L. et al. (2014) Global Causes of Maternal Death: A WHO Systematic Analysis, Lancet Glob Health, 2, e323-e333. https://doi.org/10.1016/S2214-109X(14)70227-X

[2] Phipps, E., Prasanna, D., Brima, W. and Jim, B. (2016) Preeclampsia: Updates in Pathogenesis, Definitions, and Guidelines. Clinical Journal of the American Society of Nephrology, 11, 1102-1113. https://doi.org/10.2215/CJN.12081115

[3] Ngoc, N.T., et al. (2006) Causes of Stillbirths and Early Neonatal Deaths: Data from 7993 Pregnancies in Six Developing Countries. Bulletin of the World Health Organization, 84, 699-705. https://doi.org/10.2471/BLT.05.027300

[4] Liberis, A., Stanulov, G., Ali, E.C., Hassan, A., Pagalos, A. and Kontomanolis, E.N. (2016) Pre-Eclampsia and the Vascular Endothelial Growth Factor: A New Aspect. Clinical and Experimental Obstetrics \& Gynecology, 43, 9-13.

[5] Rosas-Peralta, M., Borrayo-Sanchez, G., Madrid-Miller, A., Ramirez-Arias, E. and Perez-Rodriguez, G. (2016) Cardiovascular Complications of Hypertensive Crisis. Revista Medica Del Instituto Mexicano Del Seguro Social, 54, s67-s74.

[6] Reeves, I.V., Bamji, Z.D., Rosario, G.B., Lewis, K.M., Young, M.A. and Washington, K.N. (2014) Vitamin D deficiency in Pregnant Women of Ethnic Minority: A Potential Contributor to Preeclampsia. Journal of Perinatology, 34, 767-773. https://doi.org/10.1038/jp.2014.91

[7] LaMarca, B., Amaral, L.M., Harmon, A.C., Cornelius, D.C., Faulkner, J.L. and Cunningham Jr., M.W. (2016) Placental Ischemia and Resultant Phenotype in Animal Models of Preeclampsia. Current Hypertension Reports, 18, 38. https://doi.org/10.1007/s11906-016-0633-x

[8] Backes, C.H., Markham, K., Moorehead, P., Cordero, L., Nankervis, C.A. and Giannone, P.J. (2011) Maternal Preeclampsia and Neonatal Outcomes. Journal of Pregnancy, 2011, Article ID: 214365. https://doi.org/10.1155/2011/214365

[9] Burger, D. and Touyz, R.M. (2012) Cellular Biomarkers of Endothelial Health: Microparticles, Endothelial Progenitor Cells, and Circulating Endothelial Cells. Journal of the American Society of Hypertension, 6, 85-99.

https://doi.org/10.1016/j.jash.2011.11.003

[10] Poss, K.D. and Tonegawa, S. (1997) Reduced Stress Defense in Heme Oxygenase 1-Deficient Cells. Proceedings of the National Academy of Sciences of the United States of America, 94, 10925-10930. https://doi.org/10.1073/pnas.94.20.10925

[11] Berhan, Y. (2016) No Hypertensive Disorder of Pregnancy; No Preeclampsia-Eclampsia; No Gestational Hypertension; No Hellp Syndrome. Vascular Disorder of Pregnancy Speaks for All. Ethiopian Journal of Health Sciences, 26, 177-186. https://doi.org/10.4314/ejhs.v26i2.12

[12] Cheng, M., He, P. and Fu, J. (2016) The Relationship between Circulating Tissue Transglutaminase, Soluble Fms-Like Tyrosine Kinase-1, Soluble Endoglin and Vascular Endothelial Growth Factor in Pre-Eclampsia. Journal of Human Hypertension, 30, 788-793. https://doi.org/10.1038/jhh.2016.32

[13] Roberts, J.M., Taylor, R.N., Musci, T.J., Rodgers, G.M., Hubel, C.A. and McLaughlin, M.K. (1989) Preeclampsia: An Endothelial Cell Disorder. American Journal of Obstetrics and Gynecology, 161, 1200-1204.

https://doi.org/10.1016/0002-9378(89)90665-0

[14] Venkatesha, S., et al. (2006) Soluble Endoglin Contributes to the Pathogenesis of Preeclampsia. Nature Medicine, 12, 642-649. https://doi.org/10.1038/nm1429

[15] Bartsch, E., Medcalf, K.E., Park, A.L. and Ray, J.G. (2016) Clinical Risk Factors for 
Pre-Eclampsia Determined in Early Pregnancy: Systematic Review and Meta-Analysis of Large Cohort Studies. BMJ, 353, i1753. https://doi.org/10.1136/bmj.i1753

[16] Cheng, S.B. and Sharma, S. (2016) Preeclampsia and Health Risks Later in Life: An Immunological Link. Seminars in Immunopathology, 38, 699-708. https://doi.org/10.1007/s00281-016-0579-8

[17] Redman, C.W. and Sargent, I.L. (2003) Pre-Eclampsia, the Placenta and the Maternal Systemic Inflammatory Response-A Review. Placenta, 24, S21-S27. https://doi.org/10.1053/plac.2002.0930

[18] Kudo, Y., Boyd, C.A., Kimura, H., Cook, P.R., Redman, C.W. and Sargent, I.L. (2003) Quantifying the Syncytialisation of Human Placental Trophoblast BeWo Cells Grown in vitro. Biochimica et Biophysica Acta, 1640, 25-31. https://doi.org/10.1016/S0167-4889(03)00004-1

[19] Silasi, M., Cohen, B., Karumanchi, S.A. and Rana, S. (2010) Abnormal Placentation, Angiogenic Factors, and the Pathogenesis of Preeclampsia. Obstetrics and Gynecology Clinics of North America, 37, 239-253. https://doi.org/10.1016/j.ogc.2010.02.013

[20] Dekker, G.A., et al. (1995) Underlying Disorders Associated with Severe Early-Onset Preeclampsia. American Journal of Obstetrics and Gynecology, 173, 1042-1048. https://doi.org/10.1016/0002-9378(95)91324-6

[21] Bainbridge, S.A., Deng, J.S. and Roberts, J.M. (2009) Increased Xanthine Oxidase in the Skin of Preeclamptic Women. Reproductive Sciences, 16, 468-478. https://doi.org/10.1177/1933719108329817

[22] Roberts, J.M. and Hubel, C.A. (2009) The Two Stage Model of Preeclampsia: Variations on the Theme. Placenta, 30, S32-S37. https://doi.org/10.1016/j.placenta.2008.11.009

[23] LaMarca, B., et al. (2016) Identifying Immune Mechanisms Mediating the Hypertension during Preeclampsia. American Journal of Physiology-Regulatory, Integrative and Comparative Physiology, 311, R1-R9. https://doi.org/10.1152/ajpregu.00052.2016

[24] Harmon, A.C., et al. (2016) The Role of Inflammation in the Pathology of Preeclampsia. Clinical Science, 130, 409-419. https://doi.org/10.1042/CS20150702

[25] Duley, L. (2009) The Global Impact of Pre-Eclampsia and Eclampsia. Seminars in Perinatology, 33, 130-137. https://doi.org/10.1053/j.semperi.2009.02.010

[26] Esplin, M.S., et al. (2001) Paternal and Maternal Components of the Predisposition to Preeclampsia. The New England Journal of Medicine, 344, 867-872. https://doi.org/10.1056/NEJM200103223441201

[27] Dave, A., Maru, L. and Jain, A. (2016) LDH (Lactate Dehydrogenase): A Biochemical Marker for the Prediction of Adverse Outcomes in Pre-Eclampsia and Eclampsia. The Journal of Obstetrics and Gynecology of India, 66, 23-29. https://doi.org/10.1007/s13224-014-0645-x

[28] Connolly, K.A., Factor, S.H., Getrajdman, C.S., Bigelow, C.A., Weintraub, A.S. and Stone, J.L. (2016) Maternal Clinical Disease Characteristics and Maternal and Neonatal Outcomes in Twin and Singleton Pregnancies with Severe Preeclampsia. European Journal of Obstetrics \& Gynecology and Reproductive Biology, 201, 36-41. https://doi.org/10.1016/j.ejogrb.2015.11.031

[29] Lim, J.H., et al. (2011) Association between Genetic Polymorphisms in Androgen Receptor Gene and the Risk of Preeclampsia in Korean Women. Journal of Assisted 
Reproduction and Genetics, 28, 85-90. https://doi.org/10.1007/s10815-010-9485-5

[30] Blazquez, A., Garcia, D., Rodriguez, A., Vassena, R., Figueras, F. and Vernaeve, V. (2016) Is Oocyte Donation a Risk Factor for Preeclampsia? A Systematic Review and Meta-Analysis. Journal of Assisted Reproduction and Genetics, 33, 855-863. https://doi.org/10.1007/s10815-016-0701-9

[31] Baker, A.M., Haeri, S., Camargo Jr., C.A., Espinola, J.A. and Stuebe, A.M. (2010) A Nested Case-Control Study of Midgestation Vitamin D Deficiency and Risk of Severe Preeclampsia. Journal of Clinical Endocrinology and Metabolism, 95, 5105-5109. https://doi.org/10.1210/jc.2010-0996

[32] Robinson, C.J., Alanis, M.C., Wagner, C.L., Hollis, B.W. and Johnson, D.D. (2010) Plasma 25-Hydroxyvitamin D Levels in Early-Onset Severe Preeclampsia. American Journal of Obstetrics and Gynecology, 203, 366.e1-366.e6.

https://doi.org/10.1016/j.ajog.2010.06.036

[33] Bodnar, L.M., Simhan, H.N., Powers, R.W., Frank, M.P., Cooperstein, E. and Roberts, J.M. (2007) High Prevalence of Vitamin D Insufficiency in Black and White Pregnant Women Residing in the Northern United States and Their Neonates. Journal of Nutrition, 137, 447-452. https://doi.org/10.1093/jn/137.2.447

[34] Wolf, M., et al. (2004) Preeclampsia and Future Cardiovascular Disease: Potential Role of Altered Angiogenesis and Insulin Resistance. Journal of Clinical Endocrinology and Metabolism, 89, 6239-6243. https://doi.org/10.1210/jc.2004-0548

[35] Verdonk, K., Visser, W., Van Den Meiracker, A.H. and Danser, A.H. (2014) The Renin-Angiotensin-Aldosterone System in Pre-Eclampsia: The Delicate Balance between Good and Bad. Clinical Science, 126, 537-544. https://doi.org/10.1042/CS20130455

[36] Goldman-Wohl, D. and Yagel, S. (2009) Preeclampsia-A Placenta Developmental Biology Perspective. Journal of Reproductive Immunology, 82, 96-99. https://doi.org/10.1016/j.jri.2009.05.002

[37] Madhukaran, S.P., Alhamlan, F.S., Kale, K., Vatish, M., Madan, T. and Kishore, U. (2016) Role of Collectins and Complement Protein C1q in Pregnancy and Parturition. Immunobiology, 221, 1273-1288. https://doi.org/10.1016/j.imbio.2016.06.002

[38] Redman, C.W. and Sargent, I.L. (2008) Circulating Microparticles in Normal Pregnancy and Pre-Eclampsia. Placenta, 29, S73-S77. https://doi.org/10.1016/j.placenta.2007.11.016

[39] Redman, C.W. and Sargent, I.L. (2005) Latest Advances in Understanding Preeclampsia. Science, 308, 1592-1594. https://doi.org/10.1126/science.1111726

[40] Wallace, A.E., Whitley, G.S., Thilaganathan, B. and Cartwright, J.E. (2015) Decidual Natural Killer Cell Receptor Expression Is Altered in Pregnancies with Impaired Vascular Remodeling and a Higher Risk of Pre-Eclampsia. Journal of Leukocyte Biology, 97, 79-86. https://doi.org/10.1189/jlb.2A0614-282R

[41] Chan, S.Y., et al. (2015) Vitamin D Promotes Human Extravillous Trophoblast Invasion in vitro. Placenta, 36, 403-409. https://doi.org/10.1016/j.placenta.2014.12.021

[42] Tabiasco, J., et al. (2006) Human Decidual NK Cells: Unique Phenotype and Functional Properties-A Review. Placenta, 27, S34-S39. https://doi.org/10.1016/j.placenta.2006.01.009

[43] Lash, G.E., et al. (2010) Regulation of Extravillous Trophoblast Invasion by Uterine Natural Killer Cells Is Dependent on Gestational Age. Human Reproduction, 25, 1137-1145. https://doi.org/10.1093/humrep/deq050

[44] Moffett-King, A. (2002) Natural Killer Cells and Pregnancy. Nature Reviews Im- 
munology, 2, 656-663. https://doi.org/10.1038/nri886

[45] Loisel, D.A., et al. (2013) The Maternal HLA-G 1597DeltaC Null Mutation Is Associated with Increased Risk of Pre-Eclampsia and Reduced HLA-G Expression during Pregnancy in African-American Women. Molecular Human Reproduction, 19, 144-152. https://doi.org/10.1093/molehr/gas041

[46] Escudero, C.A., et al. (2016) Role of Extracellular Vesicles and microRNAs on Dysfunctional Angiogenesis during Preeclamptic Pregnancies. Frontiers in Physiology, 7, 98. https://doi.org/10.3389/fphys.2016.00098

[47] Lash, G.E. and Ernerudh, J. (2015) Decidual Cytokines and Pregnancy Complications: Focus on Spontaneous Miscarriage. Journal of Reproductive Immunology, 108, 83-89.

[48] Barrera, D., Diaz, L., Noyola-Martinez, N. and Halhali, A. (2015) Vitamin D and Inflammatory Cytokines in Healthy and Preeclamptic Pregnancies. Nutrients, 7, 6465-6490. https://doi.org/10.3390/nu7085293

[49] Lash, G.E., Naruse, K., Innes, B.A., Robson, S.C., Searle, R.F. and Bulmer, J.N. (2010) Secretion of Angiogenic Growth Factors by Villous Cytotrophoblast and Extravillous Trophoblast in Early Human Pregnancy. Placenta, 31, 545-548. https://doi.org/10.1016/j.placenta.2010.02.020

[50] Giuliani, E., Parkin, K.L., Lessey, B.A., Young, S.L. and Fazleabas, A.T. (2014) Characterization of Uterine NK Cells in Women with Infertility or Recurrent Pregnancy Loss and Associated Endometriosis. American Journal of Reproductive Immunolo$g y$, 72, 262-269. https://doi.org/10.1111/aji.12259

[51] Cavalli, R.C., et al. (2016) Induced Human Decidual NK-Like Cells Improve Utero-Placental Perfusion in Mice. PLoS ONE, 11, e0164353. https://doi.org/10.1371/journal.pone.0164353

[52] Hanna, J., et al. (2006) Decidual NK Cells Regulate Key Developmental Processes at the Human Fetal-Maternal Interface. Nature Medicine, 12, 1065-1074. https://doi.org/10.1038/nm1452

[53] Hiby, S.E., et al. (2004) Combinations of Maternal KIR and Fetal HLA-C Genes Influence the Risk of Preeclampsia and Reproductive Success. The Journal of Experimental Medicine, 200, 957-965. https://doi.org/10.1084/jem.20041214

[54] Goldman-Wohl, D.S. et al. (2000) Lack of Human Leukocyte Antigen-G Expression in Extravillous Trophoblasts Is Associated with Pre-Eclampsia. Molecular Human Reproduction, 6, 88-95. https://doi.org/10.1093/molehr/6.1.88

[55] Zehnder, D. et al. (2002) The Ontogeny of 25-Hydroxyvitamin D(3) 1alpha-Hydroxylase Expression in Human Placenta and Decidua. American Journal of Pathology, 161, 105-114. https://doi.org/10.1016/S0002-9440(10)64162-4

[56] Evans, K.N., et al. (2006) Effects of 25-Hydroxyvitamin D3 and 1,25-Dihydroxyvitamin D3 on Cytokine Production by Human Decidual Cells. Biology of Reproduction, 75, 816-822. https://doi.org/10.1095/biolreprod.106.054056

[57] Vigano, P., Mangioni, S., Pompei, F. and Chiodo, I. (2003) Maternal-Conceptus Cross Talk-A Review. Placenta, 24, S56-S61.

https://doi.org/10.1016/S0143-4004(03)00137-1

[58] Figueiredo, A.S. and Schumacher, A. (2016) The T Helper Type 17/Regulatory T Cell Paradigm in Pregnancy. Immunology, 148, 13-21. https://doi.org/10.1111/imm.12595

[59] Ernerudh, J., Berg, G. and Mjosberg, J. (2011) Regulatory T Helper Cells in Pregnancy and Their Roles in Systemic Versus Local Immune Tolerance. American 
Journal of Reproductive Immunology, 66, 31-43. https://doi.org/10.1111/j.1600-0897.2011.01049.x

[60] Joachim, R., et al. (2003) The Progesterone Derivative Dydrogesterone Abrogates Murine Stress-Triggered Abortion by Inducing a Th2 Biased Local Immune Response. Steroids, 68, 931-940. https://doi.org/10.1016/j.steroids.2003.08.010

[61] Zenclussen, A.C., Fest, S., Sehmsdorf, U.S., Hagen, E., Klapp, B.F. and Arck, P.C. (2001) Upregulation of Decidual P-Selectin Expression Is Associated with an Increased Number of Th1 Cell Populations in Patients Suffering from Spontaneous Abortions. Cellular Immunology, 213, 94-103. https://doi.org/10.1006/cimm.2001.1877

[62] Diaz, L., et al. (2009) Calcitriol Inhibits TNF-Alpha-Induced Inflammatory Cytokines in Human Trophoblasts. Journal of Reproductive Immunology, 81, 17-24. https://doi.org/10.1016/j.jri.2009.02.005

[63] Sasaki, Y., et al. (2007) Proportion of Peripheral Blood and Decidual CD4 ${ }^{+}$ CD25 ${ }^{\text {Bright }}$ Regulatory T Cells in Pre-Eclampsia. Clinical \& Experimental Immunology, 149, 139-145. https://doi.org/10.1111/j.1365-2249.2007.03397.x

[64] Kleinewietfeld, M. and Hafler, D.A. (2014) Regulatory T Cells in Autoimmune Neuroinflammation. Immunological Reviews, 259, 231-244. https://doi.org/10.1111/imr.12169

[65] Luppi, P. and Deloia, J.A. (2006) Monocytes of Preeclamptic Women Spontaneously Synthesize Pro-Inflammatory Cytokines. Clinical Immunology, 118, 268-275. https://doi.org/10.1016/j.clim.2005.11.001

[66] Faas, M.M. and de Vos, P. (2016) Maternal Monocytes in Pregnancy and Preeclampsia in Humans and in Rats. Journal of Reproductive Immunology, 119, 91-97. https://doi.org/10.1016/j.jri.2016.06.009

[67] Williams, D.J., Vallance, P.J., Neild, G.H., Spencer, J.A. and Imms, F.J. (1997) Nitric Oxide-Mediated Vasodilation in Human Pregnancy. American Journal of Physiology, 272, H748-H752. https://doi.org/10.1152/ajpheart.1997.272.2.H748

[68] Maines, M.D. (1997) The Heme Oxygenase System: A Regulator of Second Messenger Gases. Annual Review of Pharmacology and Toxicology, 37, 517-554. https://doi.org/10.1146/annurev.pharmtox.37.1.517

[69] Purcell, T.L., Given, R., Chwalisz, K. and Garfield, R.E. (1999) Nitric Oxide Synthase Distribution during Implantation in the Mouse. Molecular Human Reproduction, 5, 467-475. https://doi.org/10.1093/molehr/5.5.467

[70] Zhu, Y.C., Sun, Y., Yang, H.X. and Liao, Q.P. (2009) Profile of Serum Soluble Endoglin in Pregnant Women with Severe Pre-Eclampsia and Eclampsia. Zhonghua Fu Chan Ke Za Zhi, 44, 91-93.

[71] Fushima, T., et al. (2016) Reduced Uterine Perfusion Pressure (RUPP) Model of Preeclampsia in Mice. PLoS ONE, 11, e0155426. https://doi.org/10.1371/journal.pone.0155426

[72] Fischer, D., et al. (2007) Metabolism of Vitamin D3 in the Placental Tissue of Normal and Preeclampsia Complicated Pregnancies and Premature Births. Clinical and Experimental Obstetrics and Gynecology, 34, 80-84.

[73] Shin, J.S., Choi, M.Y., Longtine, M.S. and Nelson, D.M. (2010) Vitamin D Effects on Pregnancy and the Placenta. Placenta, 31, 1027-1034. https://doi.org/10.1016/j.placenta.2010.08.015

[74] Rebut-Bonneton, C. and Demignon, J. (1991) Effect of Calcitriol on Peripheral Blood Lymphocyte Cytotoxicity. Biomedicine \& Pharmacotherapy, 45, 369-372. 
https://doi.org/10.1016/0753-3322(91)90068-5

[75] Tamblyn, J.A., Hewison, M., Wagner, C.L., Bulmer, J.N. and Kilby, M.D. (2015) Immunological Role of Vitamin D at the Maternal-Fetal Interface. Journal of Endocrinology, 224, R107-R121. https://doi.org/10.1530/JOE-14-0642

[76] Smith, T.A., Kirkpatrick, D.R., Kovilam, O. and Agrawal, D.K. (2015) Immunomodulatory Role of Vitamin D in the Pathogenesis of Preeclampsia. Expert Review of Clinical Immunology, 11, 1055-1063. https://doi.org/10.1586/1744666X.2015.1056780

[77] Chen, X., et al. (2016) Modulatory Effects of Vitamin D on Peripheral Cellular Immunity in Patients with Recurrent Miscarriage. American Journal of Reproductive Immunology, 76, 432-438. https://doi.org/10.1111/aji.12585

[78] Qian, L., Wang, H., Wu, F., Li, M., Chen, W. and Lv, L. (2015) Vitamin D3 Alters Toll-Like Receptor 4 Signaling in Monocytes of Pregnant Women at Risk for Preeclampsia. International Journal of Clinical and Experimental Medicine, 8, 18041-18049.

[79] Levytska, K., Kingdom, J., Baczyk, D. and Drewlo, S. (2013) Heme Oxygenase-1 in Placental Development and Pathology. Placenta, 34, 291-298. https://doi.org/10.1016/j.placenta.2013.01.004

[80] Zhao, H., Wong, R.J., Kalish, F.S., Nayak, N.R. and Stevenson, D.K. (2009) Effect of Heme Oxygenase-1 Deficiency on Placental Development. Placenta, 30, 861-868. https://doi.org/10.1016/j.placenta.2009.07.012

[81] Kreiser, D., et al. (2002) Heme Oxygenase-1 Modulates Fetal Growth in the Rat. Laboratory Investigation, 82, 687-692. https://doi.org/10.1097/01.LAB.0000017167.26718.F2

[82] Watanabe, S., Akagi, R., Mori, M., Tsuchiya, T. and Sassa, S. (2004) Marked Developmental Changes in Heme Oxygenase-1 (HO-1) Expression in the Mouse Placenta: Correlation between HO-1 Expression and Placental Development. Placenta, 25, 387-395. https://doi.org/10.1016/j.placenta.2003.10.012

[83] Morse, D. and Choi, A.M. (2005) Heme Oxygenase-1: From Bench to Bedside. American Journal of Respiratory and Critical Care Medicine, 172, 660-670. https://doi.org/10.1164/rccm.200404-465SO

[84] Zhao, H., Azuma, J., Kalish, F., Wong, R.J. and Stevenson, D.K. (2011) Maternal Heme Oxygenase 1 Regulates Placental Vasculature Development via Angiogenic Factors in Mice. Biology of Reproduction, 85, 1005-1012.

https://doi.org/10.1095/biolreprod.111.093039

[85] Powe, C.E., Levine, R.J. and Karumanchi, S.A. (2011) Preeclampsia, a Disease of the Maternal Endothelium: The Role of Antiangiogenic Factors and Implications for Later Cardiovascular Disease. Circulation, 123, 2856-2869. https://doi.org/10.1161/CIRCULATIONAHA.109.853127

[86] Exner, M., Minar, E., Wagner, O. and Schillinger, M. (2004) The Role of Heme Oxygenase-1 Promoter Polymorphisms in Human Disease. Free Radical Biology and Medicine, 37, 1097-1104. https://doi.org/10.1016/j.freeradbiomed.2004.07.008

[87] Zhao, H., et al. (2008) Regulation of Maternal and Fetal Hemodynamics by Heme Oxygenase in Mice. Biology of Reproduction, 78, 744-751.

https://doi.org/10.1095/biolreprod.107.064899

[88] Bainbridge, S.A. and Smith, G.N. (2005) HO in Pregnancy. Free Radical Biology and Medicine, 38, 979-988. https://doi.org/10.1016/j.freeradbiomed.2004.11.002

[89] Udono-Fujimori, R., et al. (2004) Suppression of Cytokine-Induced Expression of 
Endothelin-1 by Dexamethasone in Human Retinal Pigment Epithelial Cells. Journal of Cardiovascular Pharmacology, 44, S471-S473. https://doi.org/10.1097/01.fjc.0000166311.53506.dd

[90] Burton, G.J., Woods, A.W., Jauniaux, E. and Kingdom, J.C. (2009) Rheological and Physiological Consequences of Conversion of the Maternal Spiral Arteries for Uteroplacental Blood Flow during Human Pregnancy. Placenta, 30, 473-482. https://doi.org/10.1016/j.placenta.2009.02.009

[91] Pileggi, A., et al. (2001) Heme Oxygenase-1 Induction in Islet Cells Results in Protection from Apoptosis and Improved in vivo Function after Transplantation. Diabetes, 50, 1983-1991. https://doi.org/10.2337/diabetes.50.9.1983

[92] Balla, J., Jacob, H.S., Balla, G., Nath, K., Eaton, J.W. and Vercellotti, G.M. (1993) Endothelial-Cell Heme Uptake from Heme Proteins: Induction of Sensitization and Desensitization to Oxidant Damage. Proceedings of the National Academy of Sciences of the United States of America, 90, 9285-9289.

[93] Denschlag, D., et al. (2004) The Size of a Microsatellite Polymorphism of the Haem Oxygenase 1 Gene Is Associated with Idiopathic Recurrent Miscarriage. Molecular Human Reproduction, 10, 211-214. https://doi.org/10.1093/molehr/gah024

[94] Ryter, S.W., Alam, J. and Choi, A.M. (2006) Heme Oxygenase-1/Carbon Monoxide: From Basic Science to Therapeutic Applications. Physiological Reviews, 86, 583-650. https://doi.org/10.1152/physrev.00011.2005

[95] Sun, J., Zhong, W., Gu, Y., Groome, L.J. and Wang, Y. (2014) 1,25(OH)2D3 SUPPRESSES COX-2 Up-Regulation and Thromboxane Production in Placental Trophoblast Cells in Response to Hypoxic Stimulation. Placenta, 35, 143-145. https://doi.org/10.1016/j.placenta.2013.12.002

[96] Walsh, S.W. (2004) Eicosanoids in Preeclampsia. Prostaglandins, Leukotrienes and Essential Fatty Acids, 70, 223-232. https://doi.org/10.1016/j.plefa.2003.04.010

[97] Song, J., Li, Y. and An, R. (2016) Vitamin D Restores Angiogenic Balance and Decreases Tumor Necrosis Factor-Alpha in a Rat Model of Pre-Eclampsia. Journal of Obstetrics and Gynaecology Research, 43, 42-49.

[98] Wang, Z., Zhang, H., Sun, X. and Ren, L. (2016) The Protective Role of Vitamin D3 in a Murine Model of Asthma via the Suppression of TGF-Beta/Smad Signaling and Activation of the Nrf2/HO-1 Pathway. Molecular Medicine Reports, 14, 2389-2396. https://doi.org/10.3892/mmr.2016.5563

[99] Endemann, D.H. and Schiffrin, E.L. (2004) Endothelial Dysfunction. Journal of the American Society of Nephrology, 15, 1983-1992. https://doi.org/10.1097/01.ASN.0000132474.50966.DA

[100] Johansen, M., Redman, C.W., Wilkins, T. and Sargent, I.L. (1999) Trophoblast Deportation in Human Pregnancy-Its Relevance for Pre-Eclampsia. Placenta, 20, 531-539. https://doi.org/10.1053/plac.1999.0422

[101] Huppertz, B., et al. (2003) Hypoxia Favours Necrotic versus Apoptotic Shedding of Placental Syncytiotrophoblast into the Maternal Circulation. Placenta, 24, 181-190. https://doi.org/10.1053/plac.2002.0903

[102] Maynard, S., Epstein, F.H. and Karumanchi, S.A. (2008) Preeclampsia and Angiogenic Imbalance. Annual Review in Medicine, 59, 61-78. https://doi:10.1146/annurev.med.59.110106.214058

[103] Rosas-Peralta, M., Borrayo-Sanchez, G., Madrid-Miller, A., Ramirez-Arias E., and Perez-Rodriguez, G. (2016) Systemic Arterial Hypertension in the Elderly. Recommendations for Clinical Practice. Revista Médica del Instituto Mexicano del Seguro 
Social, 54, s75-s77.

[104] Redman, C.W., Sacks, G.P. and Sargent, I.L. (1999) Preeclampsia: An Excessive Maternal Inflammatory Response to Pregnancy. American Journal of Obstetrics and Gynecology, 180, 499-506. https://doi.org/10.1016/S0002-9378(99)70239-5

[105] Nakagawa, T., et al. (2011) Endothelial Dysfunction as a Potential Contributor in Diabetic Nephropathy. Nature Reviews Nephrology, 7, 36-44. https://doi.org/10.1038/nrneph.2010.152

[106] Allaire, A.D., Ballenger, K.A., Wells, S.R., McMahon, M.J. and Lessey, B.A. (2000) Placental Apoptosis in Preeclampsia. Obstetrics \& Gynecology, 96, 271-276.

[107] Gauster, M., Moser, G., Orendi, K. and Huppertz, B. (2009) Factors Involved in Regulating Trophoblast Fusion: Potential Role in the Development of Preeclampsia. Placenta, 30, S49-S54. https://doi.org/10.1016/j.placenta.2008.10.011

[108] Meeme, A., Buga, G.A., Mammen, M. and Namugowa, A.V. (2016) Angiogenic Imbalance as a Contributor to the Pathophysiology of Preeclampsia among Black African Women. The Journal of Maternal-Fetal \& Neonatal Medicine, 30, 1335-1341. https://doi.org/10.1080/14767058.2016.1212832

[109] Liberis, A. (2016) Pre-Eclampsia and the Vascular Endothelial Growth Factor: A New Aspect. Clinical and Experimental Obstetrics and Gynecology, 43, 9-13.

[110] Jakovljevic, A., Bogavac, M., Lozanov-Crvenkovic, Z., Milosevic-Tosic, M., Nikolic, A.and Mitic, G. (2016) Early Pregnancy Angiogenic Proteins Levels and Pregnancy Related Hypertensive Disorders. The Journal of Maternal-Fetal \& Neonatal Medicine, 30, 534-539. https://doi.org/10.1080/14767058.2016.1177814

[111] Loukeris, K., Sela, R. and Baergen, R.N. (2010) Syncytial Knots as a Reflection of Placental Maturity: Reference Values for 20 to 40 Weeks' Gestational Age. Pediatric and Developmental Pathology, 13, 305-309. https://doi.org/10.2350/09-08-0692-OA.1

[112] Wei, S.Q., et al. (2013) Maternal Plasma 25-Hydroxyvitamin D Levels, Angiogenic Factors, and Preeclampsia. American Journal of Obstetrics and Gynecology, 208, 390.e1-390.e6. https://doi.org/10.1016/j.ajog.2013.03.025

[113] Levine, R.J., et al. (2004) Circulating Angiogenic Factors and the Risk of Preeclampsia. The New England Journal of Medicine, 350, 672-683. https://doi.org/10.1056/NEJMoa031884

[114] Lecarpentier, E. and Tsatsaris, V. (2016) Angiogenic Balance (sFlt-1/PlGF) and Preeclampsia. Annales d'Endocrinologie, 77, 97-100. https://doi.org/10.1016/j.ando.2016.04.007

[115] Chappell, L.C., et al. (2013) Diagnostic Accuracy of Placental Growth Factor in Women with Suspected Preeclampsia: A Prospective Multicenter Study. Circulation, 128, 2121-2131. https://doi.org/10.1161/CIRCULATIONAHA.113.003215

[116] Frampton, G.K., Jones, J., Rose, M. and Payne, L. (2016) Placental Growth Factor (Alone or in Combination with Soluble Fms-Like Tyrosine Kinase 1) as an Aid to the Assessment of Women with Suspected Pre-Eclampsia: Systematic Review and Economic Analysis. Health Technology Assessment, 20, 1-160. https://doi.org/10.3310/hta20870

[117] Perales, A., et al. (2016) sFlt-1/PlGF for Early-Onset Pre-Eclampsia Prediction: STEPS (Study of Early Pre-Eclampsia in Spain). Ultrasound in Obstetrics and Gynecology, 50, 373-382. https://doi.org/10.1002/uog.17373

[118] Luo, Q. and Han, X. (2016) Second-Trimester Maternal Serum Markers in the Prediction of Preeclampsia. Journal of Perinatal Medicine, 45, 809-816. 
https://doi.org/10.1515/jpm-2016-0249

[119] Woodham, P.C., et al. (2011) Midgestation Maternal Serum 25-Hydroxyvitamin D Level and Soluble Fms-Like Tyrosine Kinase 1/Placental Growth Factor Ratio as Predictors of Severe Preeclampsia. Hypertension, 58, 1120-1125. https://doi.org/10.1161/HYPERTENSIONAHA.111.179069

[120] Xu, J., et al. (2017) Vitamin D Reduces Oxidative Stress-Induced Procaspase-3/ROCK1 Activation and MP Release by Placental Trophoblasts. Journal of Clinical Endocrinology Metabolism, 102, 2100-2110. https://doi.org/10.1210/jc.2016-3753

[121] Cardus, A., et al. (2009) 1,25-Dihydroxyvitamin D3 Regulates VEGF Production through a Vitamin D Response Element in the VEGF Promoter. Atherosclerosis, 204, 85-89. https://doi.org/10.1016/j.atherosclerosis.2008.08.020

[122] Sipos, P.I., Crocker, I.P., Hubel, C.A. and Baker, P.N. (2010) Endothelial Progenitor Cells: Their Potential in the Placental Vasculature and Related Complications. Placenta, 31, 1-10. https://doi.org/10.1016/j.placenta.2009.10.006

[123] Brodowski, L., et al. (2014) Vitamin D Prevents Endothelial Progenitor Cell Dysfunction Induced by Sera from Women with Preeclampsia or Conditioned Media from Hypoxic Placenta. PLoS ONE, 9, e98527. https://doi.org/10.1371/journal.pone.0098527

[124] Aggarwal, S., Sunderland, N., Thornton, C., Xu, B., Hennessy, A. and Makris, A. (2016) A Longitudinal Analysis of Angiotensin II Type 1 Receptor Antibody and Angiogenic Markers in Pregnancy. American Journal of Obstetrics \& Gynecology, 216, 170.e1-170.e8. https://doi.org/10.1016/j.ajog.2016.10.028

[125] Fu, M.L., et al. (1999) Agonist-Like Activity of Antibodies to Angiotensin II Receptor Subtype 1 (AT1) from Rats Immunized with AT1 Receptor Peptide. Blood Pressure, 8, 317-324. https://doi.org/10.1080/080370599439544

[126] Gant, N.F., Daley, G.L., Chand, S., Whalley, P.J. and MacDonald, P.C. (1973) A Study of Angiotensin II Pressor Response throughout Primigravid Pregnancy. Journal of Clinical Investigation, 52, 2682-2689. https://doi.org/10.1172/JCI107462

[127] Andersen, L.B., et al. (2015) Vitamin D Depletion Aggravates Hypertension and Target-Organ Damage. Journal of the American Heart Association, 4, e001417. https://doi.org/10.1161/JAHA.114.001417

[128] Carrara, D., et al. (2016) Cholecalciferol Treatment Downregulates Renin-Angiotensin System and Improves Endothelial Function in Essential Hypertensive Patients with Hypovitaminosid D. Journal of Hypertension, 34, 2199-2205. https://doi.org/10.1097/HJH.0000000000001072

[129] Faulkner, J.L., et al. (2016) Vitamin D Supplementation Reduces Some AT1-AA Induced Downstream Targets Implicated in Preeclampsia Including Hypertension. American Journal of Physiology-Regulatory Integrative and Comparative Physiolo$g y, 312, \mathrm{R} 125-\mathrm{R} 131$.

[130] Park, H., et al. (2017) Maternal Vitamin D Biomarkers Are Associated with Maternal and Fetal Bone Turnover among Pregnant Women Consuming Controlled Amounts of Vitamin D, Calcium, and Phosphorus. Bone, 95, 183-191. https://doi.org/10.1016/j.bone.2016.12.002

[131] Hollis, B.W. and Wagner, C.L. (2017) New Insights into the Vitamin D Requirements during Pregnancy. Bone Research, 5, Article Number: 17030.

https://doi.org/10.1038/boneres.2017.30

[132] Colonese, F., et al. (2015) The Pleiotropic Effects of Vitamin D in Gynaecological 
and Obstetric Diseases: An Overview on a Hot Topic. BioMed Research International, 2015, Article ID: 986281. https://doi.org/10.1155/2015/986281

[133] Weintraub, S.J. (2014) Vitamin D-Binding Protein and Vitamin D in Blacks and Whites. The New England Journal of Medicine, 370, 878-881. https://doi.org/10.1056/NEJMc1315850

[134] Powe, C.E., Karumanchi, S.A. and Thadhani, R. (2014) Vitamin D-Binding Protein and Vitamin D in Blacks and Whites. The New England Journal of Medicine, 370, 880-881.

[135] Bouillon, R., Jones, K. and Schoenmakers, I. (2014) Vitamin D-Binding Protein and Vitamin D in Blacks and Whites. The New England Journal of Medicine, 370, 879-880.

[136] Hollis, B.W. and Bikle, D.D. (2014) Vitamin D-Binding Protein and Vitamin D in Blacks and Whites. The New England Journal of Medicine, 370, 879-880.

[137] Lechtermann, C., et al. (2014) Maternal Vitamin D Status in Preeclampsia: Seasonal Changes Are Not Influenced by Placental Gene Expression of Vitamin D Metabolizing Enzymes. PLoS ONE, 9, e105558. https://doi.org/10.1371/journal.pone.0105558

[138] Orton, S.M., et al. (2008) Evidence for Genetic Regulation of Vitamin D Status in Twins with Multiple Sclerosis. American Journal of Clinical Nutrition, 88, 441-447. https://doi.org/10.1093/ajcn/88.2.441

[139] Wilson, R.T., et al. (2015) Genetic and Environmental Influences on Plasma Vitamin D Binding Protein Concentrations. Translational Research, 165, 667-676. https://doi.org/10.1016/j.trsl.2014.08.003

[140] Weisman, Y., Harell, A., Edelstein, S., David, M., Spirer, Z. and Golander, A. (1979) 1 Alpha, 25-Dihydroxyvitamin D3 and 24,25-Dihydroxyvitamin D3 in vitro Synthesis by Human Decidua and Placenta. Nature, 281, 317-319. https://doi.org/10.1038/281317a0

[141] Signorello, L.B., et al. (2011) Common Variation in Vitamin D Pathway Genes Predicts Circulating 25-Hydroxyvitamin D Levels among African Americans. PLoS ONE, 6, e28623. https://doi.org/10.1371/journal.pone.0028623

[142] Haussler, M.R., et al. (1998) The Nuclear Vitamin D Receptor: Biological and Molecular Regulatory Properties Revealed. Journal of Bone and Mineral Research, 13, 325-349. https://doi.org/10.1359/jbmr.1998.13.3.325

[143] Murthi, P., et al. (2016) Role of the Placental Vitamin D Receptor in Modulating Feto-Placental Growth in Fetal Growth Restriction and Preeclampsia-Affected Pregnancies. Frontiers in Physiology, 7, 43. https://doi.org/10.3389/fphys.2016.00043

[144] Uitterlinden, A.G., Fang, Y., Van Meurs, J.B., Pols, H.A. andVan Leeuwen, J.P. (2004) Genetics and Biology of Vitamin D Receptor Polymorphisms. Gene, 338, 143-156. https://doi.org/10.1016/j.gene.2004.05.014

[145] Enquobahrie, D.A., Williams, M.A., Qiu, C., Siscovick, D.S. and Sorensen, T.K. (2011) Global Maternal Early Pregnancy Peripheral Blood mRNA and miRNA Expression Profiles according to Plasma 25-Hydroxyvitamin D Concentrations. Journal of Maternal-Fetal and Neonatal Medicine, 24, 1002-1012. https://doi.org/10.3109/14767058.2010.538454

[146] Moslehi, R., Mills, J.L., Signore, C., Kumar, A., Ambroggio, X. and Dzutsev, A. (2013) Integrative Transcriptome Analysis Reveals Dysregulation of Canonical Cancer Molecular Pathways in Placenta Leading to Preeclampsia. Scientific Reports, 
3, Article Number: 2407. https://doi.org/10.1038/srep02407

[147] Malik, S., et al. (2013) Common Variants of the Vitamin D Binding Protein Gene and Adverse Health Outcomes. Critical Reviews in Clinical Laboratory Sciences, 50, 1-22. https://doi.org/10.3109/10408363.2012.750262

[148] Baca, K.M., Govil, M., Zmuda, J.M., Simhan, H.N., Marazita, M.L. and Bodnar, L.M. (2017) Vitamin D Metabolic Loci and Vitamin D Status in Black and White Pregnant Women. European Journal of Obstetrics \& Gynecology and Reproductive Biology, 220, 61-68. https://doi.org/10.1016/j.ejogrb.2017.11.013 


\section{Abbreviations}

Ang-II-angiotensin II

AT1-angiotensin II type I receptor

AT1-AA-Angiotensin II type 1 receptor antibodies

BMI-body mass index

CAMP - cathelicidin antimicrobial peptide

CD56-cluster of differentiation molecule [NCAM (neural cell adhesion molecule)]

$\mathrm{CD} 16$-cluster of differentitaion molecule ( $\mathrm{Fc}$ receptor for IgG)

CYP27B1-cytochrome P450, family 27 , subfamily B, polypeptide 1 (25 hydroxyvitamin D3-1-alpha hydroxylase)

DCs-dendritic cells

dNK-decidual Natural Killer

ECFCs-endothelial colony forming cells

eNO-endothelial nitric oxide

ET-1-endothelin-1

EVT-extravillous trophoblasts

FACS-Fluorescence Activated Cell Sorter"

GC genes-group-specific globulin component

HO-1-Heme oxygenase-1

HLA-G-Human leukocyte antigen (major histocompatibility antigen, alpha chain $G$ )

HLA-C-Human leukocyte antigen (major Histocompatibility Complex, Class I,

C)

ICAM-1-intercellular Adhesion Molecule-1

IgG-immunoglobulin, class gamma

IL-2-interleukin-2 ( $\mathrm{T}$ cell growth factor)

IL-4-interleukin-4 (LSF1, Lymphocyte Stimulatory Factor 1)

IL-6-interleukin-6 (Interferon Beta-2)

IL-10-interleukin-10 (CSIF, Cytokine Synthesis Inhibitory Factor)

IL-17-interleukin-17 (CTLA-8, cytotoxic T lymphocyte antigen)

IFN- $\gamma$-interferon-gamma

iNO-inducible nitric oxide

KIR2DL4-inhibitory killer-cell immunoglobulin-like receptors

LDH-lactate dehydrogenase

PAI-1-plasminogen activator inhibitor-1

$\mathrm{PE}$ - preeclampsia

PGI-prostacyclin

PlGF-phosphatidylinositol glycan anchor biosynthesis class F

RAAS-renin-angiotensin-aldosterone system

ROS-reactive oxygen species

sEng-soluble endoglin

SNP_single nucleotide polymorphisms

TGF- $\beta$-transforming growth factor beta 1 
Th1-CD4 ${ }^{+} \mathrm{T}$-helper cell, IL-1 producing population $\mathrm{Th} 2-\mathrm{CD} 4^{+} \mathrm{T}$-helper cell, IL-2 producing population

Th17-CD $4^{+} \mathrm{T}$-helper cell, IL-17 producing population

TNF- $\alpha$-tumor necrosis factor-alpha

TLR4-toll-like receptor 4

Tregs-regulatory T cells

tTG-transglutaminase

TXA-arachidonic acid thromboxane

VCAM-1-vascular adhesion Molecule-1

VDR-Vitamin D receptor

VDRE-Vitamin D response element

VEGF-vascular endothelial growth factor

VEGFR2-VEGF receptor type 2

uNK-uterine Natural Killer 